\title{
Serum and Pulmonary Uric Acid in Pulmonary Arterial Hypertension
}

\author{
Running title: Savale et al.; Role of Urate in PAH
}

\begin{abstract}
Laurent Savale ${ }^{1,2,3}$, Satoshi Akagi ${ }^{1,2}$, Ly Tu ${ }^{1,2}$, Amélie Cumont ${ }^{1,2}$, Raphaël Thuillet ${ }^{1,2}$, Carole Phan ${ }^{1,2}$, Benjamin Le Vely ${ }^{1,2}$, Nihel Berrebeh ${ }^{1,2}$, Alice Huertas ${ }^{1,2,3}$, Xavier Jaïs ${ }^{1,2,3}$, Vincent Cottin ${ }^{4}$, Ari Chaouat ${ }^{5}$, Cécile Tromeur 6 , Athénaïs Boucly ${ }^{1,2,3}$, Etienne Marie Jutant ${ }^{1,2,3}$, Olaf Mercier ${ }^{1,2,7}$, Elie Fadel $^{1,2,7}$, David Montani ${ }^{1,2,3}$, Olivier Sitbon ${ }^{1,2,3}$, Marc Humbert ${ }^{1,2,3}$, Yuichi Tamura ${ }^{1,2,8}$, Christophe
\end{abstract} Guignabert ${ }^{1,2}$

1- Université Paris-Saclay, School of Medicine, Le Kremlin-Bicêtre, France

2- INSERM UMR_S 999 «Pulmonary Hypertension: Pathophysiology and Novel Therapies», Hôpital Marie Lannelongue, Le Plessis-Robinson, France

3- Assistance Publique - Hôpitaux de Paris (AP-HP), Department of Respiratory and Intensive Care Medicine, Pulmonary Hypertension National Referral Center, Hôpital Bicêtre, Le Kremlin-Bicêtre, France.

4- Université Claude-Bernard Lyon 1, Hôpital Louis-Pradel, service de pneumologie, Centre de référence national des maladies pulmonaires rares, UMR154, Lyon, France.

5- Université de Lorraine; Département de pneumologie, CHRU de Nancy; Inserm U1116, Vandœuvre-lès-Nancy, France.

6- European Brittany University, Brest, France; Department of Internal Medicine and Chest Diseases, University Hospital Centre La Cavale Blanche, Brest, France; Groupe d'Etude de la Thrombose de Bretagne Occidentale (GETBO), EA 3878, CIC INSERM 1412, Brest, France.

7- Department of Thoracic and Vascular Surgery and Heart-Lung Transplantation, Hôpital Marie Lannelongue, Le Plessis Robinson, France, Groupe Hospitalier Paris Saint Joseph

8- Pulmonary Hypertension Center, International University of Health and Welfare Mita Hospital, Tokyo, Japan

\section{Correspondence and reprint request:}

Laurent Savale, MD, PhD

Service de Pneumologie et Soins Intensifs Respiratoires

Hôpital Bicêtre, 78, Rue du Général Leclerc, 94270 Le Kremlin-Bicêtre, France

Tel: +33.1.45.21.79.72; Fax: +33.1.45.21.79.71

E-mail : laurent.savale@aphp.fr 


\section{Take home message $(\max 251)$}

UA level is associated with poor prognosis at first follow-up in PAH. Local UA production is increased in the remodeled pulmonary vasculature and inhibition of UA incorporation in PA-SMCs reduces their proliferation and mildly reduces experimental $\mathrm{PH}$. 


\section{Abstract}

Rationale - Earlier studies have suggested an association between uric acid (UA) and pulmonary arterial hypertension (PAH) severity, but it remains unknown whether UA contributes to the disease pathogenesis.

Objectives - To study the prognostic values of circulating UA at era of current management of PAH and investigate the role of UA in the pulmonary vascular remodelling.

Methods - Serum UA levels were determined in idiopathic, heritable, or anorexigen PAH at baseline and first re-evaluation in the French $\mathrm{PAH}$ registry. We studied protein levels of xanthine oxidase (XO) and the URATV1 transporter in lungs of control and PAH patients and of monocrotaline (MCT) and sugen/hypoxia (SuHx) rats. Functional studies were performed using human pulmonary artery smooth muscle cells (PA-SMCs) and two animal models of pulmonary hypertension $(\mathrm{PH})$.

Results - High serum UA levels are associated with a poor prognosis at first follow-up, but not at baseline. Both the generating enzyme XO and URATV1 are upregulated in the wall of remodeled pulmonary arteries in IPAH patients and MCT and SuHx rats. High UA concentrations promote a mild increase in cell growth in IPAH PA-SMCs, but not in control PA-SMCs. Consistent with these observations, we demonstrate that oxonic acid-induced hyperuricemia did not aggravate MCTinduced $\mathrm{PH}$ in rats. Finally, we show that chronic treatments of MCT and SuHx rats with benzbromarone mildly attenuate pulmonary vascular remodelling.

Conclusions - UA levels in iPAH patients is associated with impaired clinical and hemodynamic profile and might be used as a noninvasive indicator of clinical prognostic during follow-up. Our findings also indicate that metabolism of UA is disturbed in remodeled pulmonary vascular walls in both experimental and human $\mathrm{PAH}$.

\section{Key words}

Pulmonary hypertension • Smooth muscle cell • Proliferation • Urate • URATV1/SLC2A9 


\section{Introduction}

Pulmonary arterial hypertension (PAH) is a severe and devastating condition characterized by a progressive structural and functional remodelling of distal pulmonary arteries leading to progressive right heart failure, functional decline, and, ultimately, death [1]. Recent therapeutic advances in PAH management underlined the need to develop new tools for risk stratification at baseline and during follow-up [2]. Therefore, there is increasing interest in the use of biomarkers for delineating the severity and prognosis of disease, and for monitoring the course of PAH and its response to therapy [3].

The process underlying the irreversible remodelling of the pulmonary vasculature in PAH is ascribed to the increased proliferation, migration and survival of pulmonary vascular cells within the pulmonary artery wall, including of endothelial and smooth muscle cells in the pulmonary vascular wall [4]. Although the exact mechanisms remain unclear, accumulating data suggest that oxidative stress and metabolic dysfunction are the major contributors for the development and progression of $\mathrm{PAH}$. Despite the association of serum uric acid (UA) levels, the end product of the metabolism of purine compounds, with several cardiovascular diseases [5] including PAH [6-11], it remains controversial as to whether UA may modulate pathogenic mechanisms underlying the progression of these diseases. Elevated UA levels have indeed long been known to be a poor prognostic sign in idiopathic $\mathrm{PAH}$, before the era of current therapeutic management [9]. Recently, circulating UA levels have also been documented as a prognostic factor in other forms of $\mathrm{PAH}$, such as $\mathrm{PAH}$ associated with connective tissue disease [7]. Moreover, evidence supporting a direct pathogenic role for UA in PAH pathophysiology has accumulated over the years. A recent metabolomic analysis identified xanthine, an immediate precursor of UA, as a prognostic factor in PAH independent of renal function and diuretic use [12]. Nevertheless, it is unknown whether UA acts directly on pulmonary artery smooth muscle cells (PA-SMCs) contributed to pulmonary vascular remodelling.

The objectives of this translational study were to analyze the prognostic impact of UA at baseline and during follow-up in the French $\mathrm{PH}$ registry in patients with idiopathic, heritable, or anorexigen- 
associated PAH and to determine whether UA and its voltage-driven urate transporter 1 (URATV1) contributes to the pulmonary vascular remodelling in $\mathrm{PAH}$.

\section{Methods}

\section{Study population}

All experimental studies using human samples comply with the Declaration of Helsinki and were approved by the local ethics committee (Comité de Protection des Personnes [CPP] Ile-de-France VII). All patients gave informed consent before the study. The data collected were anonymized and complied with the requirements of the 'Commission Nationale Informatique et Libertés', the organization dedicated to privacy, information technology and civil rights in France. The committee approved the methods used to collect and analyze the data on 24 May 2003 (approval number 842063).

Incident, treatment naïve patients with idiopathic, heritable or anorexigen-induced $\mathrm{PAH}$ recorded in the French Pulmonary Hypertension Network registry from 2006 to 2016 were retrospectively reviewed and enrolled if a dosage of circulating UA was available at baseline and/or at the time of the first follow-up. Patients were eligible for inclusion if they had a baseline right heart catheterization confirming newly diagnosed precapillary pulmonary hypertension (known as $\mathrm{PAH}$ ) defined by a resting mean pulmonary artery pressure $(\mathrm{mPAP}) \geq 25 \mathrm{mmHg}$, pulmonary artery wedge pressure $\leq 15$ $\mathrm{mmHg}$ and pulmonary vascular resistance (PVR) $>3$ Wood units, in the absence of other known causes of pulmonary hypertension (PH). Characteristics, including demographics, cardiovascular comorbidities and variables related to PAH (Modified New York Heart Association functional class, physical examination, routine blood tests, non-encouraged 6-min walk test and standard cardiopulmonary hemodynamic variables assessed by right heart catheterization), were recorded at the same time of UA level measurement. Risk assessment was performed according to the 2015 ESC/ERS pulmonary hypertension guidelines [13]. We evaluated the presence of four low-risk criteria which were defined as 1) WHO/NYHA functional class I or II, 2) 6-min walk distance (6-MWD) >440 $\mathrm{m}, 3$ ) right atrial pressure (RAP) $<8 \mathrm{mmHg}$ and 4) cardiac index $(\mathrm{Cl}) \geq 2.5 \mathrm{~L} \cdot \mathrm{min}^{-1} \cdot \mathrm{m}^{-2}$ as previously 
described [2]. Patients were classified according to the number of low-risk criteria present at baseline (i.e. at the time of $\mathrm{PAH}$ diagnosis) and at the time of re-evaluation.

\section{Animals and in vivo treatment}

The in vivo protocol was approved by the Animal Ethics Committee of the Univ. Paris-Saclay, Le Plessis-Robinson, France. Young male Wistar rats (100 g, Janvier Labs, Saint Berthevin, France) were injected with monocrotaline (MCT) or were subjected to the VEGF receptor antagonist SU5416 followed by 3 weeks of hypoxia ( $\mathrm{SuHx}$ ) to induce severe forms of $\mathrm{PH}$. Male rats were used to minimize hormonal effects (e.g., of estrogen). For the MCT model, a single subcutaneous injection of vehicle or MCT (40 mg/kg; Sigma-Aldrich) was performed. Then, rats were assigned to either an untreated control group or a group that received a daily oral administration of vehicle (dimethyl sulfoxide:water, $1: 4, \mathrm{v}: \mathrm{v}$ ) or benzbromarone (BBR; $10 \mathrm{mg} / \mathrm{kg} /$ day for 3 weeks) (Figure $6 \mathrm{~A}$ ). BBR is a uricosuric agent that exerts its hypouricemic action solely by blocking tubular reabsorption of UA by inhibiting the URATv1 transporter. An additional group of MCT-injected rats was daily treated by oxonic acid (OA) at the dose of $750 \mathrm{mg} / \mathrm{kg} /$ day (drinking water) for 3 weeks. OA is an inhibitor of uricase leading to an increase in UA level in rats. OA treatment was initiated 1 week before MCT injection to ensure an optimal increase in serum UA level (Figure 5A). To validate our findings obtained in the MCT rat model, a second rat model of severe $\mathrm{PH}$ was used. Briefly, rats received a single subcutaneous injection of SU5416 $(20 \mathrm{mg} / \mathrm{kg})$ and were exposed to normobaric hypoxia for 3 weeks before to return to room air for 5 weeks. At 5-weeks post-SU5416 injection, pulsed-wave doppler during transthoracic echocardiography was used to validate the presence of established $\mathrm{PH}$ by assessing pulmonary artery acceleration time (AT) to right ventricular ejection time (ET) ratio, using Vivid E9 (GE Healthcare, Velizy-Villacoublay, France). Then, SuHx rats were randomized to receive vehicle or BBR (10 $\mathrm{mg} / \mathrm{kg} /$ day for 3 weeks).

At the end of treatment protocols, rats were blindly analyzed under inhalation of isoflurane $(2.0 \%$ in room air), and a polyvinyl catheter was introduced into the right jugular vein and pushed through the right ventricle into the pulmonary artery to measure the mPAP. Cardiac output (CO) in rats was measured using the thermodilution method. After measurement of hemodynamic parameters, the 
thorax was opened and the left lung immediately removed and frozen. The right lung was fixed in the distended state with formalin buffer. The right ventricular hypertrophy was assessed by the Fulton Index and the percentage of wall thickness $[(2 \times$ medial wall thickness/ external diameter $) \times 100]$ and percentages of wall thickness and of muscularized vessels were determined.

\section{Uric Acid Assay, Western blot, and Immunostaining}

Serum UA concentrations were evaluated using a specific uric acid assay kit (QuantiChrom ${ }^{\mathrm{TM}}$ Uric Acid Assay Kit, BioAssays Systems, Hayward, CA) according to the manufacturer instructions. Human lung tissue samples were obtained from Hôpital Marie Lannelongue, Le Plessis Robinson, France. For the preparation of whole lung homogenates, tissues were homogenized and sonicated in RIPA buffer containing protease and phosphatase inhibitors and $30 \mu \mathrm{g}$ of protein was used to detect URATv1 (1:400) (MBL, Cat\#:BMP027) and xanthine oxidase (XO) (1:400) (Santa Cruz, Cat\#:SC20991), and $\beta$-actin (1:50,000). Immunohistochemistry staining for URATV1 and XO were performed in human and rat lung paraffin sections. Briefly, lung sections $(5-\mu m$ thickness) were deparaffinized and stained with H\&E (Sigma-Aldrich), Sirius red, or incubated with retrieval buffer. Then sections were saturated with blocking buffer and incubated overnight with specific antibodies, followed by corresponding secondary fluorescent-labeled antibodies (Thermo Fisher Scientific). Mounting was done using ProLong Gold Antifade reagent containing DAPI (Thermo Fisher Scientific Inc.). Images were taken using an LSM700 confocal microscope (Zeiss). Other lung sections were used for immunochemistry using a VECTASTAIN ABC kit according to the manufacturer's instructions (Vector Laboratories) and counterstained with hematoxylin (Sigma-Aldrich). Images were taken using an Eclipse 80i microscope (Nikon Instruments).

Isolation and culture of human pulmonary artery-smooth muscle cells (PA-SMCs) and pulmonary endothelial cells (ECs)

Human PA-SMCs were isolated from explants of small pulmonary arteries $(0.5 \mathrm{~mm}$ internal diameter) microdissected from lung explants of $\mathrm{PAH}$ patients $(n=11)$ or from lung specimens obtained during lobectomy or pneumonectomy at a distance from the tumor foci in control subjects (Hôpital Marie 
Lannelongue, Le Plessis Robinson, France) ( $n=10)$. Preoperative echocardiography was performed in these control patients to rule out $\mathrm{PH}$ and the absence of tumoral infiltration was retrospectively established in all tissue sections by the histopathological analysis. Briefly, as previously described [14], small pieces of freshly isolated arteries were cultured in DMEM media supplemented with 10\% of fetal calf serum (FCS), 2 mM L-glutamine and antibiotics. The isolated pulmonary PA-SMCs were strongly positive for alpha-smooth muscle actin ( $\alpha-S M A)$, smooth muscle specific SM22 protein and calponin and negative for von Willebrand factor and CD31. Human pulmonary ECs were isolated and cultured as previously described [3-5]. The isolated ECs were strongly positive for acetylated lowdensity lipoprotein coupled to Alexa 488 (Alexa488-Ac-LDL), von Willebrand factor (VWF), CD31, and for Ulex europaeus agglutinin-1 (UEA-1) and negative for alpha-smooth muscle actin ( $\alpha-S M A)$. Cells were used at passage $<7$.

\section{Cell Proliferation Assays}

Cells proliferation was measured by 5-bromo-2-deoxyuridine (BrdU) incorporation and by cell counting. BrdU staining was measured by the DELFIA Cell proliferation kit (PerkinElmer, Courtaboeuf, France) and a time-resolved fluorometer EnVision ${ }^{\mathrm{TM}}$ Multilabel Reader (PerkinElmer). To suppress URATV1 expression, PA-SMCs were transfected using lipofectamine RNAiMAX with $100 \mathrm{nM}$ of URATv1 siRNA or with a scrambled sequence (Invitrogen, Cergy-Pontoise, France). The cells were studied within 3 days after transfection. Suppression of URATV1 levels was documented 72 hours after transfection.

\section{Measurement of Reactive Oxygen Species (ROS)}

The superoxide indicator dihydroethidium (DHE; Thermo Fisher Scientific, Saint Aubin, France) was used to evaluate intracellular ROS in cultured human PA-SMCs. Cells $(10,000 \mathrm{cell} / \mathrm{mL})$ were seeded in a 4-well Lab-Tek chamber slides and treated with increasing doses of $U A(3,6,9,12 \mathrm{mg} / \mathrm{dL}$ in media containing $0.1 \%$ bovine serum albumin (BSA) for $30 \mathrm{~min}$ at $37^{\circ} \mathrm{C}$. DHE $(10 \mu \mathrm{M})$ was added and incubated for $20 \mathrm{~min}$ at $37^{\circ} \mathrm{C}$. After incubation, the cells were washed twice with PBS and the LabTek is mounted with ProLong Gold Antifade reagent containing DAPI (Thermo Fisher Scientific Inc.) 
and the mean of fluorescence, that is proportional to the intracellular superoxide production, was determined.

\section{Statistical analyses}

Continuous variables were expressed as mean \pm standard deviation (SD) or standard error (SEM) for normally distributed variables or median (interquartile range, IQR) for non-normally distributed variables as indicated in figure and table legends. Categorical variables were expressed as number of patients and relative frequencies (percent). For each experiment, the ranges of $\mathrm{n}$ in all groups was expressed in figure legends ( $n=$ min-max)._Differences in continuous variables were compared using the independent Student's t-test for normally distributed variables and the Mann-Whitney U test for non-normally distributed variables. All comparisons were two sided with a p-value $<0.05$ considered significant.

Data were collected from the web-based French Registry (PAH Tool; Inovultus, Santa Maria da Feira, Portugal) and were stored in a personal computer-based data spreadsheet. Median value of UA at baseline was determined distinctly in males and females. Patients were classified according to the level of circulating UA higher or lower than the median value at first evaluation. Clinical characteristics, comorbidities and hemodynamics were compared between the two groups. Overall survival time was calculated from the date of PAH diagnostic or first re-evaluation to the date of last follow-up or death. The Kaplan-Meier method was used to estimate the proportion of patients surviving at each time point. Survival curves were compared with log-rank test.

Univariable analysis based on the Cox proportional hazards model was used to examine the relationship between survival and selected demographic, medical history and variables including UA level at baseline and at first re-evaluation after PAH therapies initiation. Multivariable analyses based on the Cox proportional hazards regression model were used to examine the independent effect of each variable on survival, controlling for possible confounding variables. We incorporated into the multivariable models modifiable and non-modifiable prognostic parameters commonly used in PAH risk assessment as well as variables that can impact UA level. Potential confounders of the relationship between UA and survival were limited to 1 per 10 events. Variables were eligible for entry 
into the multivariable models only if they were not highly correlated (absolute value of Pearson's or Spearman's rho $<0.6$ ) with other continuous variables and if $<25 \%$ of individuals had missing values for that variable. Results with $p$ values of less than 0.05 were considered statistically significant.

\section{Results}

Between January 1, 2006 and March 30, 2016, we identified 330 incident patients with idiopathic (iPAH) ( $n=238)$, heritable $(\mathrm{hPAH})(\mathrm{n}=38)$ or anorexigen-induced PAH $(n=54)$ enrolled in the French registry who had both a baseline measurement of UA and a baseline evaluation including right heart catheterization, 6-MWD and WHO/NYHA functional class. At baseline, the median value or UA level was $8.2 \mathrm{mg} / \mathrm{dL}$ (IQR; 6.9-9.7) in male and 7.3 mg/dL (IQR; 5.9-8.8) in female. One hundred and sixtythree patients had a re-evaluation of PAH within one year after diagnosis and a serum UA measurement. The median time between baseline and first re-evaluation was 4.4 months (IQR; 3.86.5). At first follow-up, median value of UA was $8.3 \mathrm{mg} / \mathrm{dL}$ (IQR; 7.2-9.8) in male and $6.8 \mathrm{mg} / \mathrm{dL}$ (IQR; 5.4-7.9) in female.

\section{Uric acid and PAH severity}

Comparison of baseline characteristics between patients with UA levels higher and lower than the median value is reported in Table 1. Patients with high serum UA level at time of PAH diagnosis had a significant higher body mass index $(B M I)(p=0.03)$, had more frequently a diabetes $(p=0.007)$ and a significantly lower 6-MWD ( $p=0.005)$. Hemodynamic measurements showed a higher RAP $(p=0.002)$ and a lower cardiac index $(\mathrm{Cl})(p=0.006)$ and biological measurements showed a higher proportion of high level of BNP or NT-proBNP $(p=0.03)$ in patients with high level of UA. At diagnosis, the proportion of patients with no or one low-risk criteria was $55 \%$ in the group with low level of UA and $66 \%$ in the group of high level of UA respectively (Figure 1A). 
At first re-evaluation, patients with high level of UA were significantly older $(p=0.01)$ and had more frequently diabetes $(p<0.001)$ and hypertension $(p=0.01)$. 6-MWD was significantly lower in patients with persistent high level of UA $(p=0.001)$. High level of UA was also associated with a higher proportion of patients with no or one low-risk criteria (30\% versus 22\%) (Figure 1B).

\section{Uric Acid and survival}

The median time of follow-up after PAH diagnosis was 58 months (IQR; 35-77). During this period, 137 events were recorded including 7 lung transplantations and 133 deaths. UA level higher than median value at time of $\mathrm{PAH}$ diagnosis was not associated with higher mortality or transplantation $(p=0.33)$ (Figure 1C). Univariable analysis for clinical, hemodynamic and biological variables including UA are reported in supplemental table 1. UA, analysed as continuous variable was not associated with prognosis $(p=0.18)$. Moreover, no relationship between UA and survival without transplantation was found after adjustment for demographic characteristics and comorbidities (i.e age, sexe, BMI, diabetes and hypertension), for hemodynamic variables (RAP, PCWP, mPAP and Cl), for non-invasive prognostic factors listed in ESC/ERS guidelines (NYHA-FC, 6 MWD and BNP/NTproBNP) and for therapies (diuretics and PAH therapies) (Table 2).

The median time of follow-up after first re-evaluation was 57 months (IQR; 35-72). During this period, 60 events were recorded including 7 lung transplantations and 53 deaths. UA level higher than median value was associated with higher mortality at first re-evaluation $(p=0.02)$ (Figure 1D). In addition, univariable analysis found a significant relationship between UA, analysed as continuous variable, and survival (HR 1.004, 95\% IC 1.002-1.006, $p=0.003)$ (Supplemental table 1). Prognostic value of UA was attenuated after adjustment for age, sex and comorbidities (HR 1.002, 95\% IC 1.000-1.005, $p=0.067)$, persisted after adjustment for hemodynamic variables (HR 1.004, 95\% IC 1.001-1.006, $p=0.0019)$ or for therapies (HR 1.003, 95\% IC 1.001-1.005, $p=0.004)$. However, prognostic value of UA did not persist after adjustment for non-invasive prognostic factors listed in ERS/ESC guidelines (6 MWD, NYHA-FC and BNP/NT-proBNP) (Table 2). 


\section{Local UA production in the pulmonary vasculature of patients with idiopathic PAH}

To test whether dysfunctional pulmonary vascular cells in iPAH produce UA in vivo, confocal microscopic analyses and double labeling with either xanthine oxidase (XO) and for the efflux transporter URATV1 (GLUT9/SLC2A9) was performed in paraffin-embedded lung specimens from iPAH and control patients. We found strong staining for $\mathrm{XO}$, the enzyme known to catalyze the hydroxylation of hypoxanthine to xanthine and xanthine to UA, and URATV1 in the smooth muscle cell layer of remodeled distal pulmonary arteries iPAH when compared with controls (Figure 2A), suggesting an abnormal local UA production and overabundance in $\mathrm{PAH}$. These in situ observations were replicated in vitro, with cultured PA-SMCs from patients iPAH exhibiting increased protein levels of XO and URATV1 compared with control PA-SMCs (Figure 2B). Consistent with an upregulation of the local UA production in iPAH, we found higher UA levels in conditioned media from cultured human PA-SMCs derived from iPAH patients compared to those of control PA-SMCs (Figure 2C).

Consistent with our results obtained with iPAH PA-SMCs, a higher intracellular UA level was noted in PA-ECs in iPAH combined with an increased protein level of XO. However, a decreased protein level of URATV1 was found in iPAH pulmonary ECs compared with control pulmonary ECs (Sup. Figure 1).

\section{High UA concentrations promote cell growth and ROS production in IPAH PA-SMCs}

Since proliferation and oxidative stress of PA-SMCs contribute to vascular remodelling in PAH $[4,15$, 16], we next questioned whether this local overabundance of UA in the remodeled pulmonary vasculature could directly modulate the PA-SMC behaviors. We thus examined the effect of increasing doses of UA proliferation of cultured PA-SMCs derived from iPAH patients $(n=4)$ and controls $(n=4)$. Although UA had no effects on cell growth in control PA-SMCs, brdU incorporation was increased 1.2-, 1.2-, 1.4-, 1.5-fold in iPAH PA-SMCs exposed to UA at 3, 6, 9, and $12 \mathrm{mg} / \mathrm{dL}$, respectively (Figure $3 \mathrm{~A})$. We also found that $\mathrm{BBR}(30 \mu \mathrm{M})$, a uricosuric agent and non-competitive inhibitor of urate transporters, and URATV1 siRNA attenuated iPAH PA-SMC proliferation induced by $9 \mathrm{mg} / \mathrm{dL}$ of UA (Figure 3B-C). 
To monitor intracellular oxidative stress, we next used the redox-sensitive fluorophore hydroethidine (dihydroethidium) and noted a significant increase in intracellular ROS production in cultured iPAH PA-SMCs exposed to high UA concentrations (Sup. Figure 2).

\section{Local UA production and secretion are increased in two animal models of severe PH}

To better understand the role of UA in the pathogenesis of the disease, we next examined serum UA levels and XO and URATv1 protein levels in lungs of rats with severe $\mathrm{PH}$ induced by MCT and SuHx. Consistent with our data obtained in human samples, circulating UA levels were found to be significantly elevated 3-weeks after MCT injection compared with control rats, while UA level was similar to control at Day-1, -7 and -14 (Figure 4A and Sup. Figure 3 and 4). Interestingly, the increase in circulating UA levels were also found in SuHx rats with established $\mathrm{PH}$ compared with control rats (Figure 4B). As observed in human lung specimens, we also found increased levels of $\mathrm{XO}$ and URATV1 proteins in lungs of MCT-injected and SuHx rats compared with control rat lungs (Figure 4C-D-E and Sup. Figure 3 and 4). A Day-1, -7 and -14, XO and URATv1 expression were similar in rats treated by MCT and controls (Figure 4D).

\section{Oxonic acid-induced hyperuricemia did not aggravate the progression of MCT-induced PH in rats}

Based upon the above observations, subsequent studies were carried out to determine whether increasing UA levels with the uricase inhibitor oxonic acid (OA) would result in worsening of MCTinduced $\mathrm{PH}$ in rats. We therefore induced mild hyperuricemia in rats by providing low doses of oxonic acid for 1 week before to randomize and assign these rats to either a vehicle-treated control group or a group that received a single subcutaneous injection of MCT to induce experimental PH (Figure 5AB). After 3 weeks with oxonic acid treatment, pulmonary hemodynamic and structures were then studied. A similar decrease in AT/ET ratio and increase in MPAP, TPVR and Fulton index was observed between MCT-injected rats treated with OA compared to vehicle-treated MCT rats (Figure 5C-D). Consistent with these results, a similar increase in the percentages of medial wall thickness and of muscularized distal pulmonary arteries were noted between MCT-injected rats treated with OA 
compared to vehicle-treated MCT rats (Figure 5E-F). Taken altogether, these results support the notion that the increase in serum UA levels has no effect on pulmonary vascular remodelling in PAH.

\section{Chronic treatments of MCT-injected and SuHx rats with benzbromarone (BBR) mildly attenuate} PH

To assess the role of the increased local UA production in the pulmonary vasculature in $\mathrm{PAH}$, we next tested the effect of BBR, an uricosuric agent and inhibitor of $\mathrm{XO}$, in the two preclinical models of severe $\mathrm{PH}$ (Figure 6). First, we examined the efficacy of BBR treatments against the development of $\mathrm{PH}$ in the MCT rat model (preventive protocol) and we next studied its efficacy against the progression of $\mathrm{PH}$ in the SuHx rat model (curative protocol) (Figure 6A). At the end of these protocols, we found a significant reduction in serum UA concentrations in MCT-injected and SuHx rats treated with BBR compared with MCT-injected and SuHx rats treated with vehicle (Figure 6B). Three- and 8- weeks post-SU5416 injection, pulsed-wave Doppler during transthoracic echocardiography indicate a decrease in pulmonary AT/ET ratio in MCT-injected and SuHx rats treated with vehicle, respectively. However, chronic treatment of MCT-injected and SuHx rats with BBR significantly attenuates the decrease pulmonary AT/ET ratio (Figure 6C). Right heart catheterization indicates that the increase in TPVR in MCT-injected and SuHx rats treated with BBR is less pronounced compared with rats MCT-injected and SuHx rats treated with vehicle (Figure 6D). However, no significant difference in mPAP, CO, and Fulton index was observed between MCT-injected and SuHx rats treated with BBR and those treated with vehicle (Figure 6D). Consistent with these observations, a mild reduction in the muscularization of pulmonary arteries was observed in MCT-injected and SuHx rats treated with BBR compared with MCT-injected and SuHx rats treated with vehicle in the MCT rat model (Figure 6E-F). These results indicate a mild protective effect of BBR treatment in these two animal models of severe $\mathrm{PH}$. 


\section{Discussion}

Although PAH is often associated with hyperuricemia, it remains unknown whether serum UA levels may be always useful for risk stratification at era of modern management at baseline and during follow-up as well as if UA may contribute to progression of the pulmonary vascular remodelling. In the present study, our data indicate that high serum UA levels in patients with PAH was associated with a significant poor prognosis at first follow-up after PAH therapies initiation, but not at baseline. We also obtained additional evidence supporting the notion that UA may represent a biomarker for $\mathrm{PH}$ severity, whose metabolism is disturbed in the remodelling pulmonary vessels of PAH patients.

At present the brain natriuretic peptide (BNP) and its N-terminal prohormone fragment (NT-proBNP) are the only two biomarkers that have been listed in the last guidelines for PAH risk stratification at baseline and during follow-up [13]. Therefore, there is a clear need to develop new biomarkers that could be routinely used in clinical practice. Because earlier studies have suggested an association between serum UA levels and the severity of PAH [6-11], the prognostic value of circulating UA levels at baseline and during follow-up has been studied in our large cohort of PAH patients. Our data show that patients with high level of UA at baseline had more severe hemodynamic impairment (i.e. higher level of RAP and lower $\mathrm{Cl}$ ), as well as more severe 6-MWD impairment. Paradoxically, high UA level at baseline was not associated with poorer prognosis, in contrast to what it has been previously described before the modern management of $\mathrm{PAH}[8,9]$. However, the persistence of a high UA level at first follow-up after the initiation of $\mathrm{PAH}$-targeted therapies is associated with more severe prognosis. It is important to underline that initial treatment strategy may explain the lack of independent association between baseline UA level and outcomes, given that disease severity has likely influenced treatment decisions. Similarly, it has been also observed that hemodynamic variables are useful to guide the choice of first line therapy but are now more effective for risk stratification at first follow-up after PAH-targeted therapies initiation [2, 17]. We also analyzed by univariable and multivariable analysis the usefulness of UA in the risk stratification method using hemodynamics, NYHA-FC and 6-MWD at first follow-up. UA was independently associated with patient prognosis when adjusted for hemodynamic variables. In a non-invasive approach including BNP/NT-proBNP, 
NYHA-FC and 6-MWD, UA was not an independent predictive factor of mortality. In this method of risk stratification, BNP/NT-proBNP seem to be more robust to predict survival of patients.

We recognize that there are limitations inherent to the retrospective nature of this study and the lack of data for noninvasive variables in $23 \%$ of patients that can limit the powerful of the multivariable analysis. Moreover, a substantial proportion of patients had UA measurement at baseline but not at follow-up. Another limitation of our study is the lack of information on renal function that could also influence the level of UA.

UA is a heterocyclic compound that is produced during the breakdown of purines, which represents the last product of purine metabolism in humans. A high-purine diet, obesity, insulin resistance, dyslipidemia, diabetes, use of diuretics, chronic renal failure, and high alcohol intake are known common causes of hyperuricemia [18-21]. PAH registries and clinical trials indicated that the proportion of elderly patients with cardiovascular risk factors progressively is increasing [22-24]. Elevated UA level is also associated with higher frequency of cardiovascular risk comorbidities, as hypertension or diabetes, that could also influence the prognosis of patients. Because UA is higher in men and postmenopausal women, due to estrogen-induced increase in renal urate elimination [25], we separately analyzed the median value of UA in each cohort according to gender of patients.

Both vasoconstriction and enhanced accumulation of PA-SMCs within the vascular wall contribute to the progressive course of $\mathrm{PH} / \mathrm{PAH}$. Interestingly, it has been reported that induction of mild hyperuricemia in rats induced by oxonic acid is associated with development of small-vessel disease in the kidney consisting of thickening of the preglomerular arteries with smooth muscle cell proliferation [26, 27]. These observations strongly suggest that UA may contribute to progressive renal disease. Based on these findings and the observation that an elevated UA is associated with the severity of $\mathrm{PAH}$, we questioned whether UA may have a direct pathogenic role and contribute to the pulmonary vascular remodelling associated with $\mathrm{PAH}$. In line with this notion, it was reported that UA could stimulate SMC proliferation by increasing the production of Ang-II, COX2, ET-1, PDGF, and ROS and activation of different pathways including among others the extracellular signal-regulated protein kinase (ERK) and p38 kinase pathways, the NF-KB and c-Jun/AP-1 pathways [27-35]. 
However, our in vitro studies indicate that UA exert a significant but rather small pro-proliferative effect on PA-SMCs derived from iPAH patients and has no effect on control PA-SMCs. In order to explain these differences between control and IPAH PA-SMCs, we explore the expressions of $\mathrm{XO}$ and URATV1 and found an upregulation of OA and URATV1 in the smooth muscle layer of remodeled vessels in iPAH and in the two animal models of severe PH. Hypoxia, TNF, IFN-gamma, IL-6, IL-1, and dexamethasone are known modulators of XO expression and activity [36-39], but further studies are needed to identify the mechanisms underlying these XO and URATV1 upregulation in remodeled vessels in PAH. Our results indicate that pulmonary ECs derived from iPAH patients also exhibited higher intracellular UA levels together with elevated XO levels and lower URATv1 levels. Since high UA concentrations has been reported to modulate the amount of NO release and the expression eNOS protein, but also on the production of ROS, the secretion of inflammatory cytokines (IL-6 and TNF- $\alpha$ ) and the expression of adhesion molecules (ICAM-1 and VCAM-1) in HUVECs and other EC types [40-42], further work is needed to investigate the role of UA in pulmonary endothelial dysfunction in $\mathrm{PH} / \mathrm{PAH}$.

To assess the role of elevated UA levels in the progression of $\mathrm{PAH}$, we next treated MCT-injected rats with oxonic acid and studied the effect of mild hyperuricemia on the severity of experimental $\mathrm{PH}$ by assessing pulmonary hemodynamics and vascular remodelling. Our data indicate that oxonic acidinduced hyperuricemia did not aggravate the progression of MCT-induced $\mathrm{PH}$ in rats. A similar increase in the percentages of medial wall thickness and of muscularized distal pulmonary arteries were found in MCT-injected rats treated with OA compared to vehicle-treated MCT rats, supporting that in vivo high UA concentrations do not contribute to the MCT-induced vascular remodelling. Since no SuHx rats were treated with OA, we cannot exclude that oxonic acid-induced hyperuricemia would have accelerate vascular remodeling in SuHx rats. In line with this notion, we found that chronic administration of BBR in MCT-injected and SuHx rats mildly attenuate $\mathrm{PH}$. BBR is a known uricosuric agent and a non-competitive inhibitor of $\mathrm{XO}$ [43]. In the MCT rat model, chronic BBR treatment partially prevented the increase in total pulmonary vascular resistance in MCT-injected rats, with a trend toward a decrease in mPAP and an increase in cardiac output. These data were consistent with the observation that chronic administration of BBR in SuHx rats with established $\mathrm{PH}$ leads to a trend 
toward improvement in hemodynamic parameters and significant reductions in the percentages of medial wall thickness and of muscularized arterioles. However, recent evidence suggests that these observed beneficial effects of BBR treatment could be also due to inhibition of the $\mathrm{Ca}^{2+}$ activated $\mathrm{Cl}^{-}$ channel, TMEM16A [44]. BBR is indeed an inhibitor of TMEM16A at micromolar concentrations [45]. Recently, Papp et al. [44] have reported that chronic administration of BBR partially reverses $\mathrm{PH}$ in both the chronic hypoxia mouse and MCT rat models through inhibition of TMEM16A. Using cultured PAH PA-SMCs, these authors have demonstrated that BBR normalizes membrane potential and blocks the PDGF induced proliferation. Despite the fact that BBR has multiple modes of action, our results indicate that elevated UA has a negligible role on the pulmonary vascular remodelling in $\mathrm{PAH}$.

In summary, we obtained several evidence showing that UA is increased in patients with PAH and correlated with survival after PAH therapies initiation and might be used as a noninvasive indicator of disease severity. Although experimental hyperuricemia did not influence pulmonary vascular remodeling in monocrotaline-injected rats, our findings indicate that production and metabolism of UA are disturbed in the wall of remodeled pulmonary arteries in MCT and SuHx rats as well as in iPAH patients. 


\section{Acknowledgments:}

The authors acknowledge Laurence Rottat (AP-HP, Hôpital Bicêtre, Le Kremlin-Bicêtre, France) for her help in obtaining the data for this study and her hard work in managing data in the French $\mathrm{PH}$ Registry. They also thank all participants to the French PH Network. The authors also thank Dr. Vincent Thomas de Montpreville, Dr. Maria-Rosa Ghigna (Hôpital Marie Lannelongue, Le PlessisRobinson, France) and all technicians and pathologists from the Department of Pathology at Marie Lannelongue hospital for their expertise and support.

\section{Financial Support:}

This research was supported by grants from the French National Institute for Health and Medical Research (INSERM), the University Paris-Saclay, the Marie Lannelongue Hospital, the French National Agency for Research (ANR) grant no. ANR-16-CE17-0014 (TAMIRAH) and no. ANR-18RHUS-0006 (RHU DESTINATION 2024), the Fondation de la Recherche Médicale (FRM) grant no. DEQ20150331712 (Equipe FRM 2015), and in part by the Département Hospitalo-Universitaire (DHU) Thorax Innovation (TORINO), the Assistance Publique-Hôpitaux de Paris (AP-HP), Service de Pneumologie, Centre de Référence de l'Hypertension Pulmonaire Sévère, the LabEx LERMIT (grant no ANR-10-LABX-0033), the French PAH patient association (HTAP France) and the french Fonds de Dotation "Recherche en Santé Respiratoire" - (FRSR) - Fondation du Souffle (FdS). N.B. is supported the lle-de-France Regional Council with a doctoral contract (ARDoC 2018). 


\section{References:}

1. Simonneau G, Montani D, Celermajer DS, Denton CP, Gatzoulis MA, Krowka M, Williams PG, Souza R. Haemodynamic definitions and updated clinical classification of pulmonary hypertension. Eur Respir J 2019; 53.

2. Boucly A, Weatherald J, Savale L, Jais X, Cottin V, Prevot G, Picard F, de Groote P, Jevnikar M, Bergot E, Chaouat A, Chabanne C, Bourdin A, Parent F, Montani D, Simonneau G, Humbert M, Sitbon O. Risk assessment, prognosis and guideline implementation in pulmonary arterial hypertension. Eur Respir J 2017; 50.

3. Savale L, Guignabert C, Weatherald J, Humbert M. Precision medicine and personalising therapy in pulmonary hypertension: seeing the light from the dawn of a new era. Eur Respir Rev 2018; 27.

4. Humbert M, Guignabert C, Bonnet S, Dorfmuller P, Klinger JR, Nicolls MR, Olschewski AJ, Pullamsetti SS, Schermuly RT, Stenmark KR, Rabinovitch M. Pathology and pathobiology of pulmonary hypertension: state of the art and research perspectives. Eur Respir J 2019; 53.

5. Feig DI, Kang DH, Johnson RJ. Uric acid and cardiovascular risk. N Engl J Med 2008; 359: 18111821.

6. Uk Kang T, Park KY, Kim HJ, Ahn HS, Yim SY, Jun JB. Association of hyperuricemia and pulmonary hypertension: A systematic review and meta-analysis. Mod Rheumatol 2019; 29: 1031-1041.

7. Simpson CE, Damico RL, Hummers L, Khair RM, Kolb TM, Hassoun PM, Mathai SC. Serum uric acid as a marker of disease risk, severity, and survival in systemic sclerosis-related pulmonary arterial hypertension. Pulm Circ 2019; 9: 2045894019859477.

8. Bendayan D, Shitrit D, Ygla M, Huerta M, Fink G, Kramer MR. Hyperuricemia as a prognostic factor in pulmonary arterial hypertension. Respir Med 2003; 97: 130-133.

9. Nagaya N, Uematsu M, Satoh T, Kyotani S, Sakamaki F, Nakanishi N, Yamagishi M, Kunieda T, Miyatake K. Serum uric acid levels correlate with the severity and the mortality of primary pulmonary hypertension. Am J Respir Crit Care Med 1999; 160: 487-492.

10. Voelkel MA, Wynne KM, Badesch DB, Groves BM, Voelkel NF. Hyperuricemia in severe pulmonary hypertension. Chest 2000; 117: 19-24.

11. Wensel R, Opitz CF, Anker SD, Winkler J, Hoffken G, Kleber FX, Sharma R, Hummel M, Hetzer $\mathrm{R}$, Ewert R. Assessment of survival in patients with primary pulmonary hypertension: importance of cardiopulmonary exercise testing. Circulation 2002; 106: 319-324.

12. Rhodes CJ, Ghataorhe P, Wharton J, Rue-Albrecht KC, Hadinnapola C, Watson G, Bleda M, Haimel M, Coghlan G, Corris PA, Howard LS, Kiely DG, Peacock AJ, Pepke-Zaba J, Toshner MR, Wort SJ, Gibbs JS, Lawrie A, Graf S, Morrell NW, Wilkins MR. Plasma Metabolomics 
Implicates Modified Transfer RNAs and Altered Bioenergetics in the Outcomes of Pulmonary Arterial Hypertension. Circulation 2017; 135: 460-475.

13. Galie N, Humbert M, Vachiery JL, Gibbs S, Lang I, Torbicki A, Simonneau G, Peacock A, Vonk Noordegraaf A, Beghetti M, Ghofrani A, Gomez Sanchez MA, Hansmann G, Klepetko W, Lancellotti P, Matucci M, McDonagh T, Pierard LA, Trindade PT, Zompatori M, Hoeper M. 2015 ESC/ERS Guidelines for the diagnosis and treatment of pulmonary hypertension: The Joint Task Force for the Diagnosis and Treatment of Pulmonary Hypertension of the European Society of Cardiology (ESC) and the European Respiratory Society (ERS): Endorsed by: Association for European Paediatric and Congenital Cardiology (AEPC), International Society for Heart and Lung Transplantation (ISHLT). Eur Respir J 2015; 46: 903-975.

14. Tu L, De Man FS, Girerd B, Huertas A, Chaumais MC, Lecerf F, Francois C, Perros F, Dorfmuller P, Fadel E, Montani D, Eddahibi S, Humbert M, Guignabert C. A critical role for p130Cas in the progression of pulmonary hypertension in humans and rodents. Am J Respir Crit Care Med 2012; 186: 666-676.

15. Oguz N, Kirca M, Cetin A, Yesilkaya A. Effect of uric acid on inflammatory COX-2 and ROS pathways in vascular smooth muscle cells. J Recept Signal Transduct Res 2017; 37: 500-505.

16. Tang L, Xu Y, Wei $\mathrm{Y}, \mathrm{He} \mathrm{X}$. Uric acid induces the expression of TNFalpha via the ROSMAPKNFkappaB signaling pathway in rat vascular smooth muscle cells. Mol Med Rep 2017; 16: 6928-6933.

17. Weatherald J, Boucly A, Chemla D, Savale L, Peng M, Jevnikar M, Jais X, Taniguchi Y, O'Connell C, Parent F, Sattler C, Herve P, Simonneau G, Montani D, Humbert M, Adir Y, Sitbon O. Prognostic Value of Follow-Up Hemodynamic Variables After Initial Management in Pulmonary Arterial Hypertension. Circulation 2018; 137: 693-704.

18. Choi HK, Atkinson K, Karlson EW, Willett W, Curhan G. Purine-rich foods, dairy and protein intake, and the risk of gout in men. N Engl J Med 2004; 350: 1093-1103.

19. Miao Z, Li C, Chen Y, Zhao S, Wang Y, Wang Z, Chen X, Xu F, Wang F, Sun R, Hu J, Song W, Yan S, Wang CY. Dietary and lifestyle changes associated with high prevalence of hyperuricemia and gout in the Shandong coastal cities of Eastern China. J Rheumatol 2008; 35: 1859-1864.

20. Rodenbach KE, Schneider MF, Furth SL, Moxey-Mims MM, Mitsnefes MM, Weaver DJ, Warady BA, Schwartz GJ. Hyperuricemia and Progression of CKD in Children and Adolescents: The Chronic Kidney Disease in Children (CKiD) Cohort Study. Am J Kidney Dis 2015; 66: 984-992.

21. De Cosmo S, Viazzi F, Pacilli A, Giorda C, Ceriello A, Gentile S, Russo G, Rossi MC, Nicolucci A, Guida P, Feig D, Johnson RJ, Pontremoli R, Group AM-AS. Serum Uric Acid and Risk of CKD in Type 2 Diabetes. Clin J Am Soc Nephrol 2015; 10: 1921-1929.

22. Hoeper MM, Simon RGJ. The changing landscape of pulmonary arterial hypertension and implications for patient care. Eur Respir Rev 2014; 23: 450-457. 
23. Rose JA, Cleveland JM, Rao Y, Minai OA, Tonelli AR. Effect of Age on Phenotype and Outcomes in Pulmonary Arterial Hypertension Trials. Chest 2016; 149: 1234-1244.

24. McLaughlin VV, Vachiery JL, Oudiz RJ, Rosenkranz S, Galie N, Barbera JA, Frost AE, Ghofrani HA, Peacock AJ, Simonneau G, Rubin LJ, Blair C, Langley J, Hoeper MM, Group AS. Patients with pulmonary arterial hypertension with and without cardiovascular risk factors: Results from the AMBITION trial. J Heart Lung Transplant 2019; 38: 1286-1295.

25. Quinones Galvan A, Natali A, Baldi S, Frascerra S, Sanna G, Ciociaro D, Ferrannini E. Effect of insulin on uric acid excretion in humans. Am J Physiol 1995; 268: E1-5.

26. Mazzali M, Kanellis J, Han L, Feng L, Xia YY, Chen Q, Kang DH, Gordon KL, Watanabe S, Nakagawa T, Lan HY, Johnson RJ. Hyperuricemia induces a primary renal arteriolopathy in rats by a blood pressure-independent mechanism. Am J Physiol Renal Physiol 2002; 282: F991-997.

27. Kang DH, Nakagawa T, Feng L, Watanabe S, Han L, Mazzali M, Truong L, Harris R, Johnson RJ. A role for uric acid in the progression of renal disease. J Am Soc Nephrol 2002; 13: 28882897.

28. Kang DH, Han L, Ouyang X, Kahn AM, Kanellis J, Li P, Feng L, Nakagawa T, Watanabe S, Hosoyamada M, Endou H, Lipkowitz M, Abramson R, Mu W, Johnson RJ. Uric acid causes vascular smooth muscle cell proliferation by entering cells via a functional urate transporter. Am J Nephrol 2005; 25: 425-433.

29. Corry DB, Eslami P, Yamamoto K, Nyby MD, Makino H, Tuck ML. Uric acid stimulates vascular smooth muscle cell proliferation and oxidative stress via the vascular renin-angiotensin system. J Hypertens 2008; 26: 269-275.

30. Chao HH, Liu JC, Lin JW, Chen $\mathrm{CH}, \mathrm{Wu} \mathrm{CH}$, Cheng TH. Uric acid stimulates endothelin-1 gene expression associated with NADPH oxidase in human aortic smooth muscle cells. Acta Pharmacol Sin 2008; 29: 1301-1312.

31. Kanellis J, Watanabe S, Li JH, Kang DH, Li P, Nakagawa T, Wamsley A, Sheikh-Hamad D, Lan HY, Feng L, Johnson RJ. Uric acid stimulates monocyte chemoattractant protein-1 production in vascular smooth muscle cells via mitogen-activated protein kinase and cyclooxygenase-2. Hypertension 2003; 41: 1287-1293.

32. Kang DH, Park SK, Lee IK, Johnson RJ. Uric acid-induced C-reactive protein expression: implication on cell proliferation and nitric oxide production of human vascular cells. $J$ Am Soc Nephrol 2005; 16: 3553-3562.

33. Price KL, Sautin YY, Long DA, Zhang L, Miyazaki H, Mu W, Endou H, Johnson RJ. Human vascular smooth muscle cells express a urate transporter. J Am Soc Nephrol 2006; 17: 17911795.

34. Sautin YY, Nakagawa T, Zharikov S, Johnson RJ. Adverse effects of the classic antioxidant uric acid in adipocytes: NADPH oxidase-mediated oxidative/nitrosative stress. Am J Physiol Cell Physiol 2007; 293: C584-596. 
35. Watanabe S, Kang DH, Feng L, Nakagawa T, Kanellis J, Lan H, Mazzali M, Johnson RJ. Uric acid, hominoid evolution, and the pathogenesis of salt-sensitivity. Hypertension 2002; 40: 355360.

36. Nanduri J, Vaddi DR, Khan SA, Wang N, Makerenko V, Prabhakar NR. Xanthine oxidase mediates hypoxia-inducible factor-2alpha degradation by intermittent hypoxia. PLoS One 2013; 8: e75838.

37. Hassoun PM, Yu FS, Shedd AL, Zulueta JJ, Thannickal VJ, Lanzillo JJ, Fanburg BL. Regulation of endothelial cell xanthine dehydrogenase xanthine oxidase gene expression by oxygen tension. Am J Physiol 1994; 266: L163-171.

38. Ghezzi P, Bianchi M, Mantovani A, Spreafico F, Salmona M. Enhanced xanthine oxidase activity in mice treated with interferon and interferon inducers. Biochem Biophys Res Commun 1984; 119: 144-149.

39. Pfeffer KD, Huecksteadt TP, Hoidal JR. Xanthine dehydrogenase and xanthine oxidase activity and gene expression in renal epithelial cells. Cytokine and steroid regulation. J Immunol 1994; 153: 1789-1797.

40. Sharaf EI Din UAA, Salem MM, Abdulazim DO. Uric acid in the pathogenesis of metabolic, renal, and cardiovascular diseases: A review. J Adv Res 2017; 8: 537-548.

41. Cai W, Duan XM, Liu Y, Yu J, Tang YL, Liu ZL, Jiang S, Zhang CP, Liu JY, Xu JX. Uric Acid Induces Endothelial Dysfunction by Activating the HMGB1/RAGE Signaling Pathway. Biomed Res Int 2017; 2017: 4391920.

42. Khosla UM, Zharikov S, Finch JL, Nakagawa T, Roncal C, Mu W, Krotova K, Block ER, Prabhakar S, Johnson RJ. Hyperuricemia induces endothelial dysfunction. Kidney Int 2005; 67: 1739-1742.

43. Sinclair DS, Fox IH. The pharmacology of hypouricemic effect of benzbromarone. $J$ Rheumatol 1975; $2:$ 437-445.

44. Papp R, Nagaraj C, Zabini D, Nagy BM, Lengyel M, Skofic Maurer D, Sharma N, Egemnazarov B, Kovacs G, Kwapiszewska G, Marsh LM, Hrzenjak A, Hofler G, Didiasova M, Wygrecka M, Sievers LK, Szucs P, Enyedi P, Ghanim B, Klepetko W, Olschewski H, Olschewski A. Targeting TMEM16A to reverse vasoconstriction and remodelling in idiopathic pulmonary arterial hypertension. Eur Respir J 2019; 53.

45. Huang F, Zhang H, Wu M, Yang H, Kudo M, Peters CJ, Woodruff PG, Solberg OD, Donne ML, Huang X, Sheppard D, Fahy JV, Wolters PJ, Hogan BL, Finkbeiner WE, Li M, Jan YN, Jan LY, Rock JR. Calcium-activated chloride channel TMEM16A modulates mucin secretion and airway smooth muscle contraction. Proc Natl Acad Sci U S A 2012; 109: 16354-16359. 


\section{Legend of figures}

Figure 1. Number of low risk criteria and survival according to serum uric acid (UA) level at baseline (A-C) and at first follow up (B-D) in incident patients with idiopathic, heritable or anorexigen-associated pulmonary arterial hypertension (PAH).

Figure 2. Increased expressions of xanthine oxidase (XO) and URATV1 in human pulmonary artery smooth muscle cells (PA-SMCs) in idiopathic pulmonary arterial hypertension (iPAH). (A) Representative images of XO (red) and URATV1 (red) in PA-SMCs (positive for alpha-smooth muscle actin ( $\alpha-S M A)$; green) in lungs from control subjects and patients with iPAH $(n=3-5)$. (B) Representative Western blots and quantification of the XO:GADPH and URATV1:GAPDH ratios in cultured PA-SMCs derived from control and iPAH patients $(n=10-12)$. (C) Conditioned media from 24 $\mathrm{h}$ serum starved PA-SMCs were measured for secreted UA levels using a specific uric acid assay. Data are presented as mean \pm SEM $(n=6-7)$. Comparisons were made using the nonparametric Mann-Whitney U test. ${ }^{*} p$-value $<0.05$ versus control PA-SMCs. Scale bar $=100 \mu \mathrm{m}$ in all sections. $\mathrm{AU}=$ arbitrary unit; DAPI = 4',6-diamidino-2-phenylindole.

Figure 3. High uric acid (UA) concentrations promote cell growth in pulmonary artery smooth muscle cells (PA-SMCs) derived from patients with idiopathic pulmonary arterial hypertension (iPAH). (A) Proliferation of PA-SMCs derived from control subjects $(n=4)$ and patients with iPAH $(n=4)$ in response to increasing doses of uric acid (UA). Proliferation of iPAH PA-SMCs in response to 9 $\mathrm{mg} / \mathrm{dL}$ of UA in presence of $30 \mu \mathrm{M}$ of BBR (B) or 48 hours after transfection with URATv1 siRNA or scrambled sequence (C) assessed by BrdU incorporation ( $n=7$ and $n=4$, respectively). Data are presented as mean \pm SEM. Comparisons were made using 1-way ANOVA with Tukey's post hoc tests. ${ }^{*} p$-value $<0.05 ;{ }^{* *} p$-value $<0.01 ;{ }^{* * *} p$-value $<0.001 ;{ }^{* * * *} p$-value $<0.0001$ versus vehicletreated cells. \#\# p-value $<0.01$ versus PA-SMCs treated with $9 \mathrm{mg} / \mathrm{dL}$ of UA. Scale bar $=20 \mu \mathrm{m}$ in all sections. $\mathrm{AU}=$ arbitrary unit. $\mathrm{ns}=$ non significant.

Figure 4. Hyperuricemia and increased lung expressions of xanthine oxidase (XO) and URATv1 in two animal models of pulmonary hypertension (PH). (A) Levels of uric acid (UA) in the serum of control animals, monocrotaline (MCT)-injected at various time points post-MCT injection $(n=5$ in all groups - one rat died prematurely at day 19 in the group Day-21). (B) Serum UA levels in control and sugen/hypoxia (SuHx) rats $(n=13-16)$. (C) Representative images of XO (red) and URATv1 (red) in PA-SMCs (positive for alpha-smooth muscle actin ( $\alpha-S M A) ;$ green) in lungs from control, MCT-injected and SuHx rats $(n=3-5)$. Scale bar $=50 \mu \mathrm{m}$ in all sections. (D-E) Representative Western blots and quantification of the XO:ß-actin and URATV1:ß-actin ratios in lungs of control, MCT-injected and SuHx rats $(n=3-5)$. Horizontal lines display the mean \pm SEM. Comparisons were made using 1-way ANOVA with Tukey's post hoc tests or the nonparametric Mann-Whitney $U$ test. * p-value <0.05, ${ }^{* *} p$-value $<0.01,{ }^{* * *} p$-value $<0.001,{ }^{* * * *} p$-value $<0.0001$ compared with control. AU = arbitrary unit; DAPI = 4',6-diamidino-2-phenylindole.

Figure 5. Oxonic acid-induced hyperuricemia did not aggravate the progression of pulmonary hypertension (PH)-induced by monocrotaline (MCT) in rats. (A) Experimental scheme and number of rats in each group. (B) Serum UA levels in control rats chronically treated with oxonic acid at Week-4 $(n=6)$. (C) Values of acceleration time (AT)/ejection time (ET) ratio obtained by transthoracic echocardiography. (D) Values of mean pulmonary arterial pressure (mPAP), cardiac output, total pulmonary vascular resistance (PVR), and of Fulton index in control and MCT-injected rats treated with oxonic acid at the indicated doses (2 hemodynamic assessments in the group $\mathrm{MCT}+\mathrm{OA}$ and 1 in the group of MCT+Vehicle are lacking due to complications related to right heart catheterization). (E) Representative images of haematoxylin and eosin (H\&E)-, $\alpha$-smooth muscle (SM) actin-stained sections of distal pulmonary arteries and (F) quantification of the percentage of wall thickness and of muscularized distal pulmonary arteries in lungs of control and MCT-injected rats treated with vehicle or oxonic acid. Scale bar $=20 \mu \mathrm{m}$ in all sections. Values are means $\pm S E M(n=4-$ 9). Comparisons were made using 1-way ANOVA with Tukey's post hoc tests or the nonparametric 
Mann-Whitney $U$ test. ${ }^{* *} p$-value $<0.01,{ }^{* * *} p$-value $<0.0001$ compared with control rats treated with vehicle. $\mathrm{AU}=$ arbitrary unit; NS = non significant.

Figure 6. Efficacy of chronic treatment with benzbromarone (BBR) in the monocrotaline (MCT) and in Sugen/Hypoxia (SuHx) rat models of severe pulmonary hypertension (PH). (A) Experimental scheme and number of rats in each group. One rat died prematurely at day 20 in the group SuHx and BBR. (B) Serum UA levels in control rats chronically treated with BBR at the end of these protocols $(n=4-7)$. (C) Values of acceleration time (AT)/ejection time (ET) ratio obtained by transthoracic echocardiography $(n=4-7)$. (D) Values of mean pulmonary arterial pressure (mPAP), cardiac output, total pulmonary vascular resistance (PVR), and of Fulton index in control and MCTinjected and SuHx rats treated with BBR or vehicle. Representative images of haematoxylin and eosin (H\&E)-, $\alpha$-smooth muscle (SM) actin-stained sections of distal pulmonary arteries and quantification of the percentage of wall thickness and of muscularized distal pulmonary arteries in lungs of control and MCT-injected $(E)$ and SuHx $(F)$ rats treated with vehicle or BBR $(n=4-7)$. Scale bar $=20 \mu \mathrm{m}$ in all sections. Values are means $\pm S E M$. Comparisons were made using 1-way ANOVA with Tukey's post hoc tests. ${ }^{*} p$-value $<0.05,{ }^{* *} p$-value $<0.01,{ }^{* * *} p$-value $<0.001,{ }^{* * * *} p$-vaalue $<0.0001$ compared with control rats treated with vehicle. \# p-value $<0.05$, \#\# p-value $<0.01$ versus vehicle-treated rats. AU $=$ arbitrary unit; NS = non significant. 
A

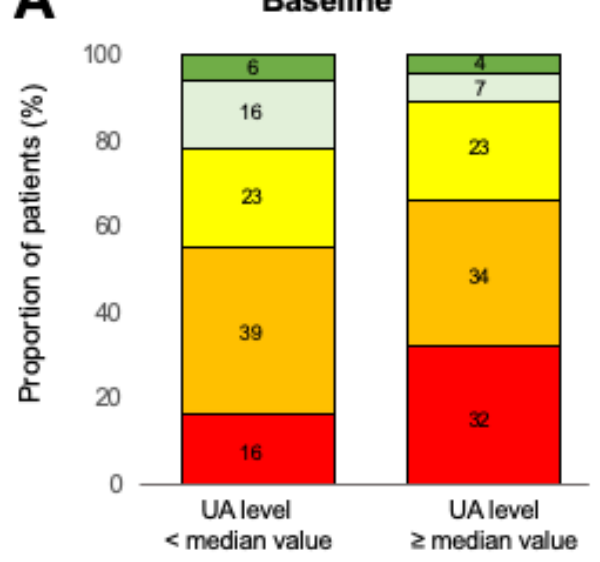

C

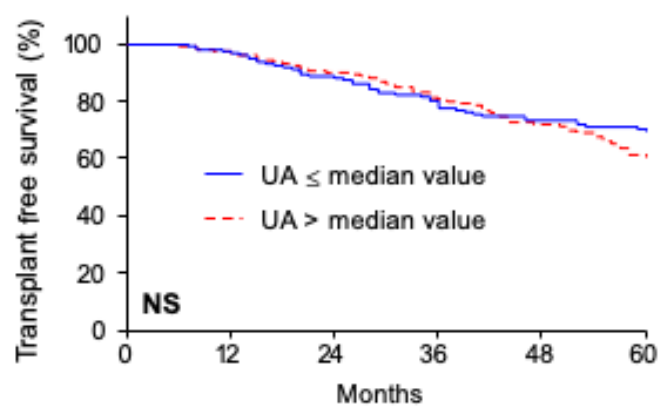

\section{B First re-evaluation}

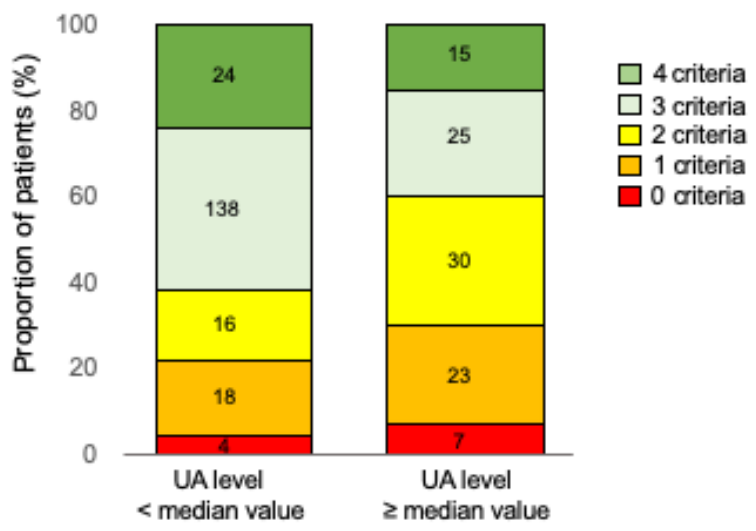

D

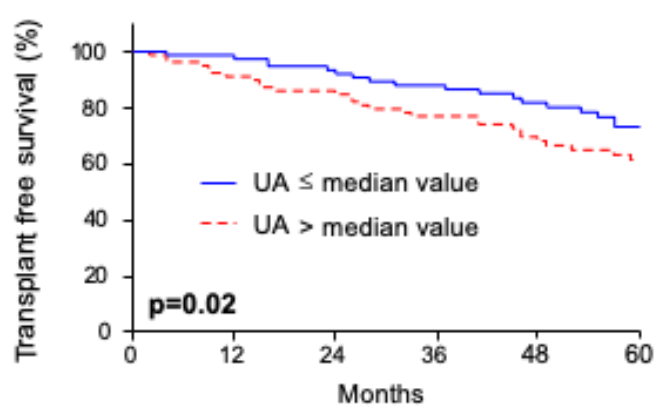



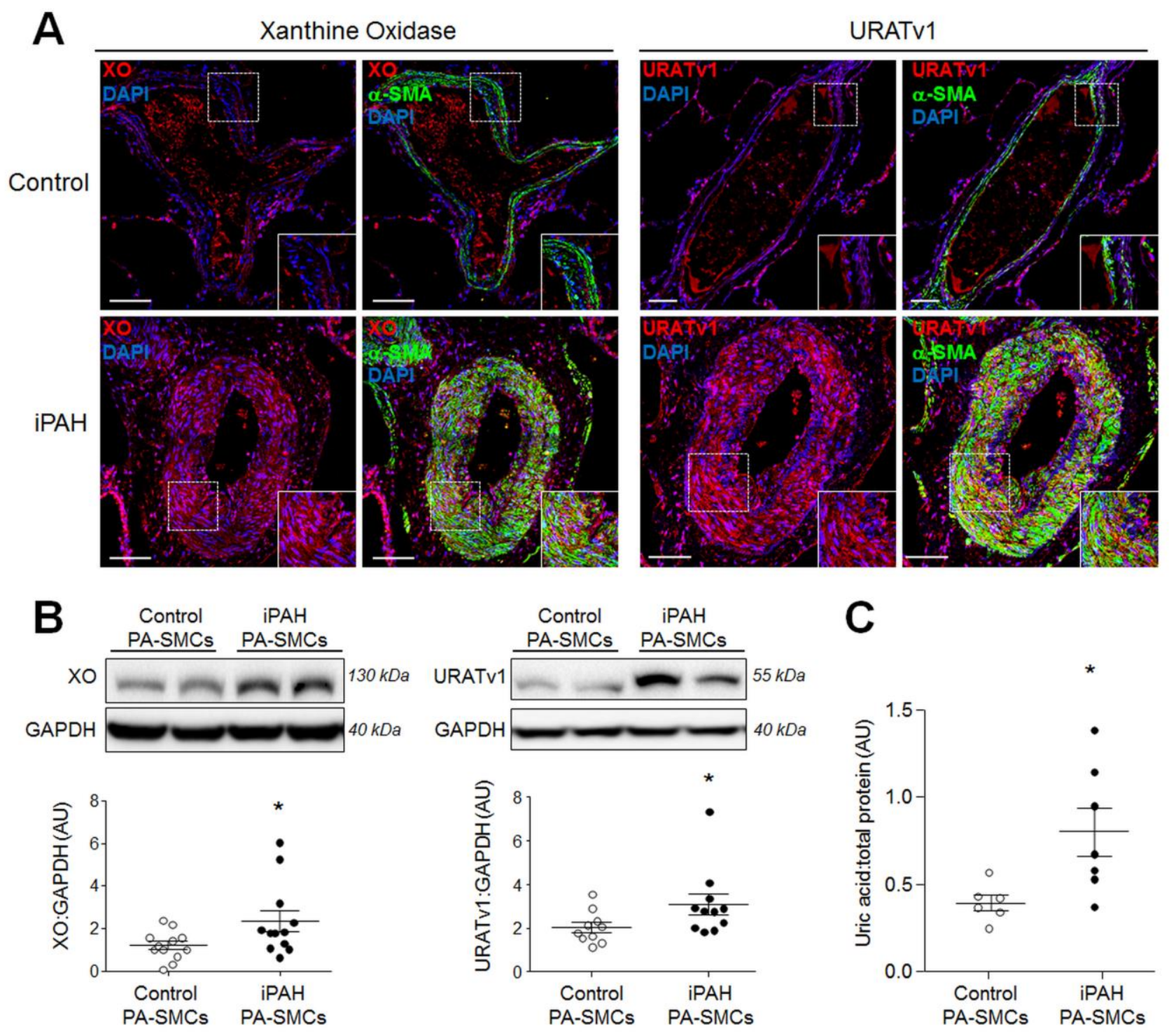

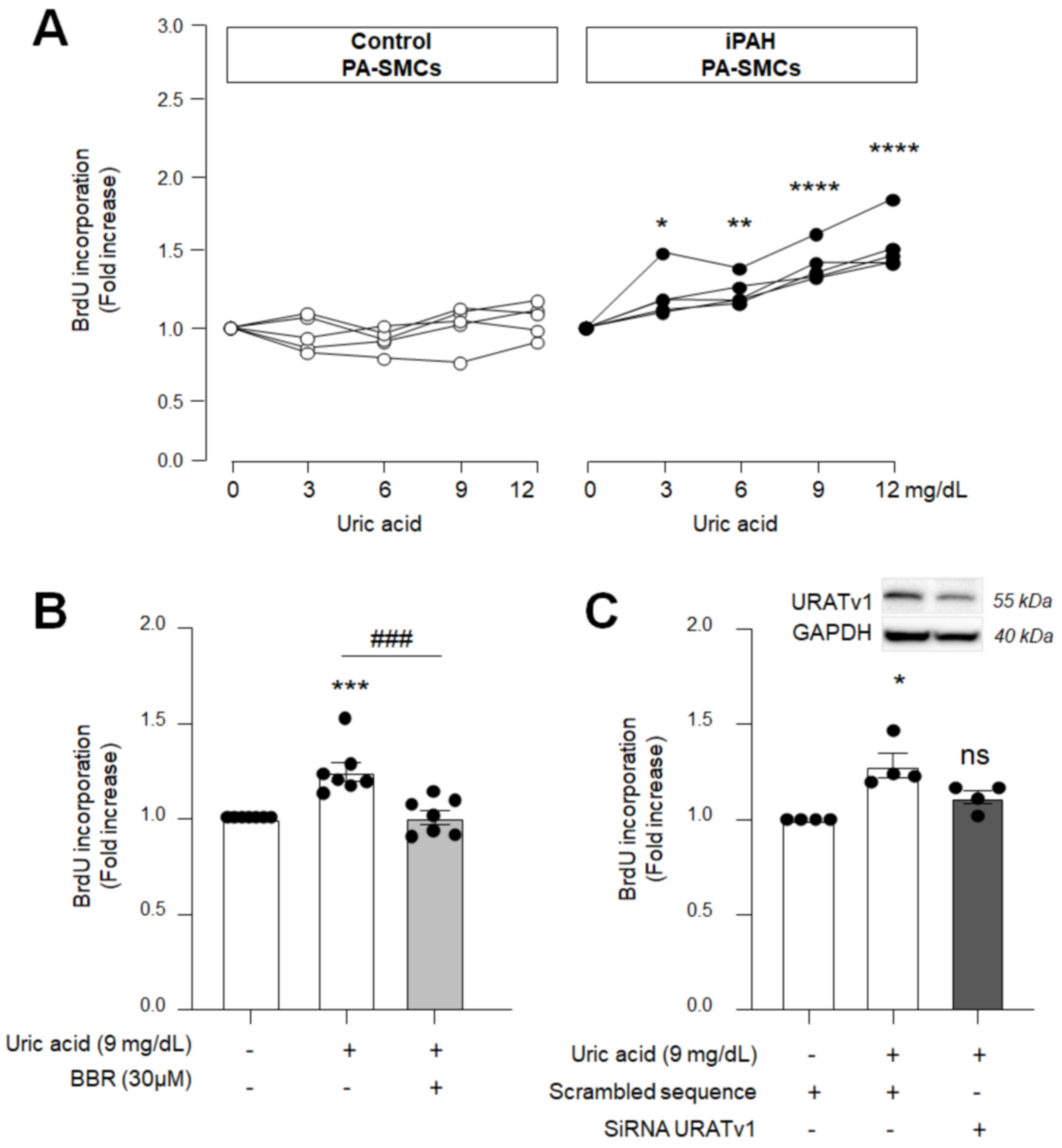


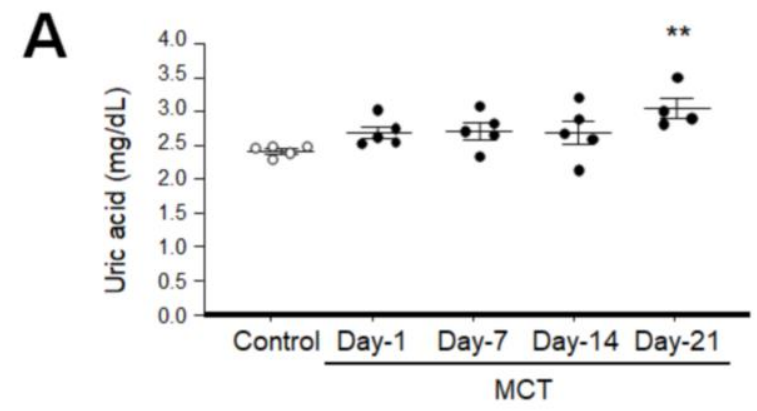

C

Control

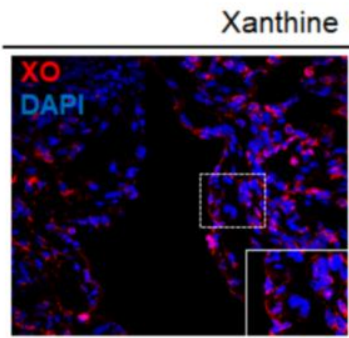

SuHx
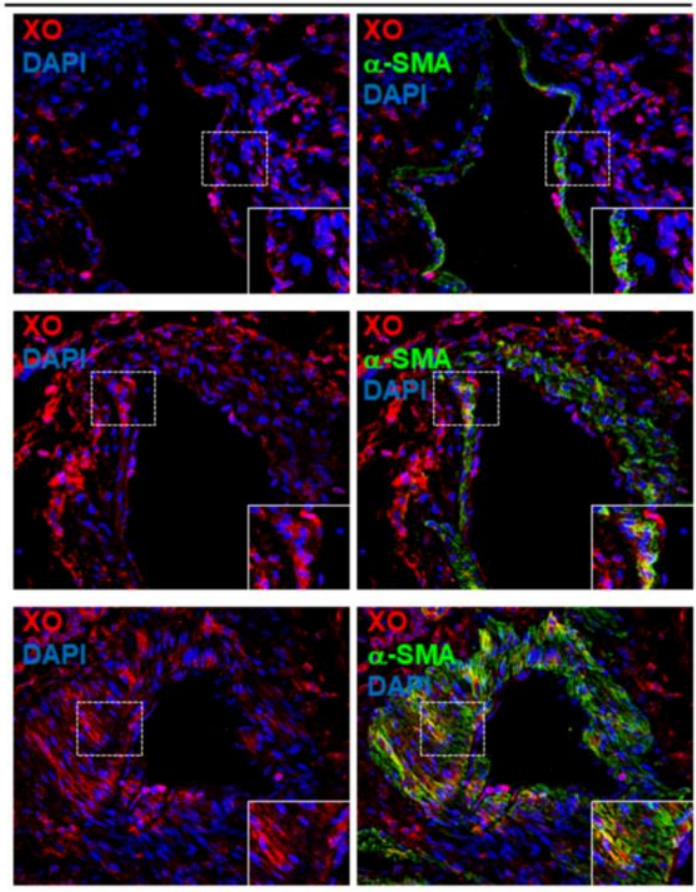

D
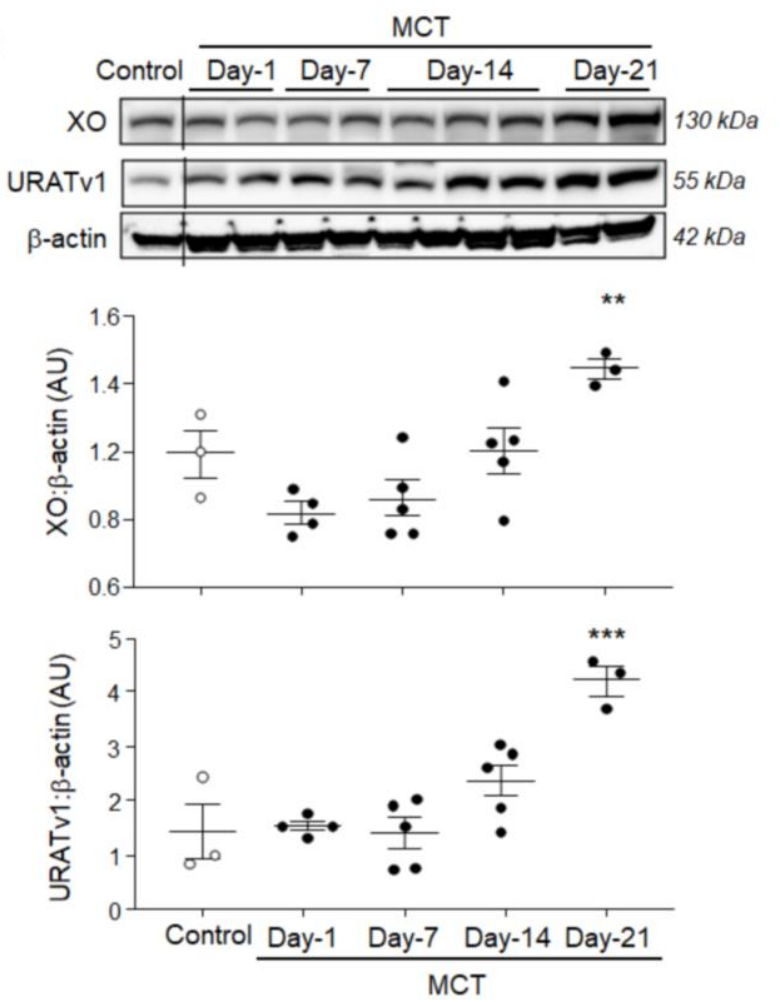

B
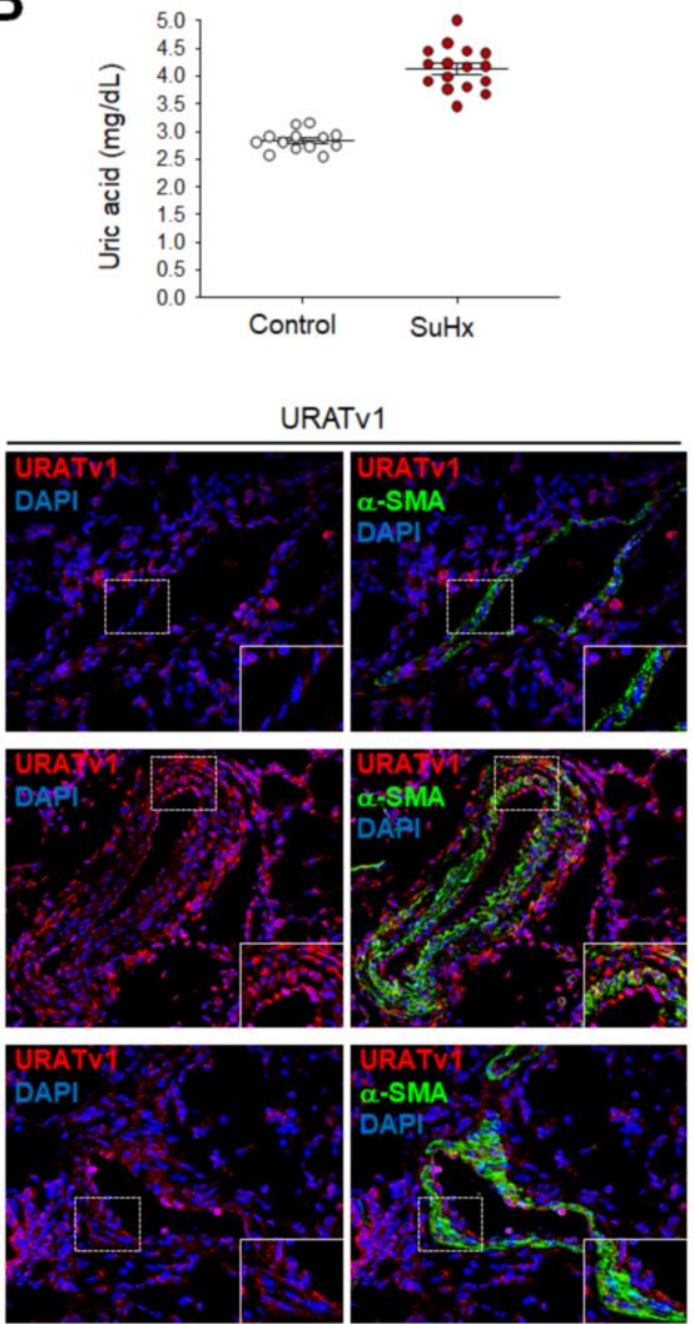

E
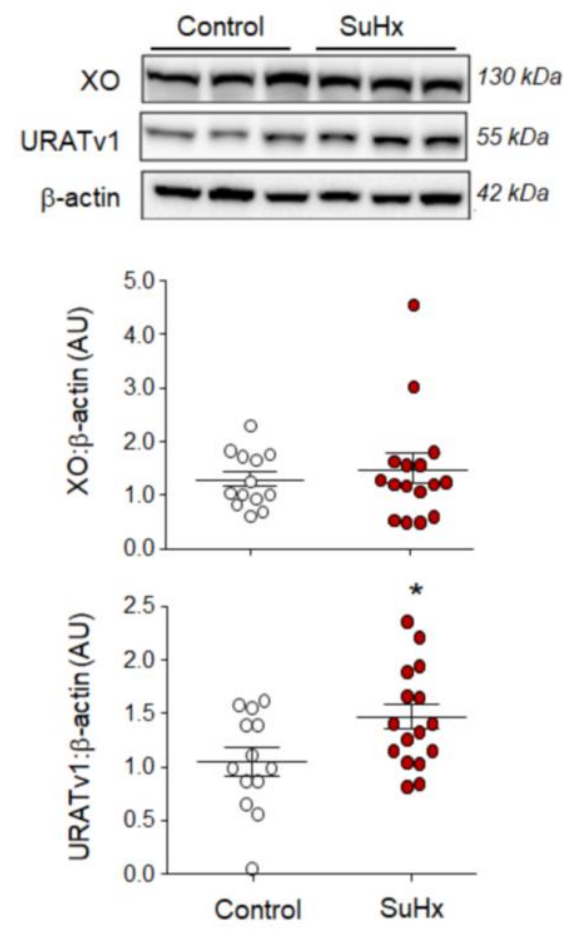
A

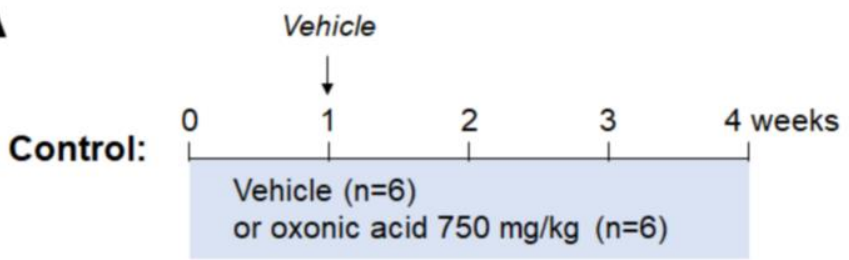

MCT:

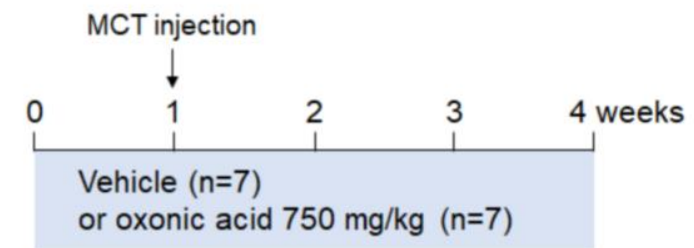

B

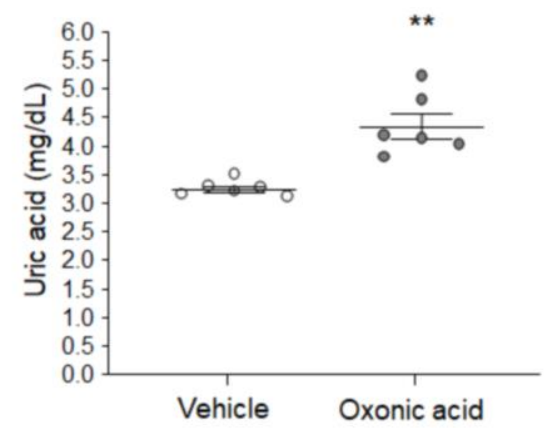

C

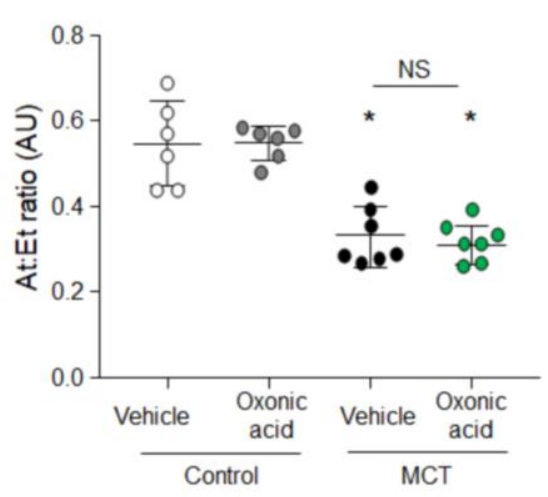

D

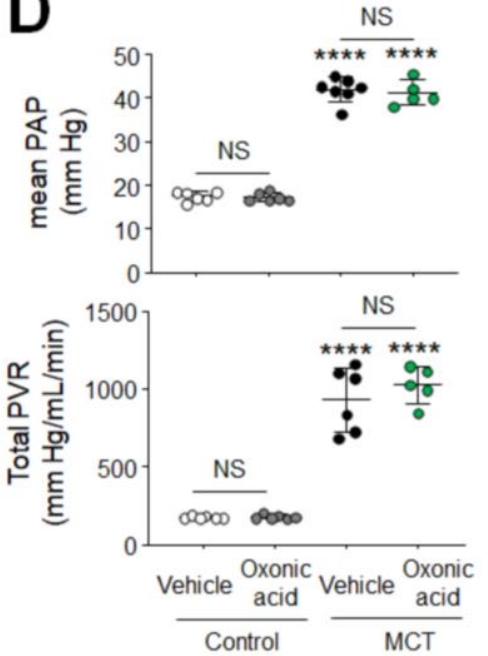

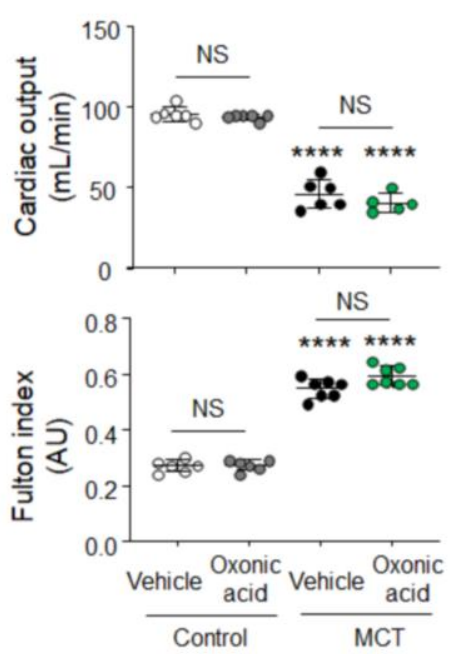
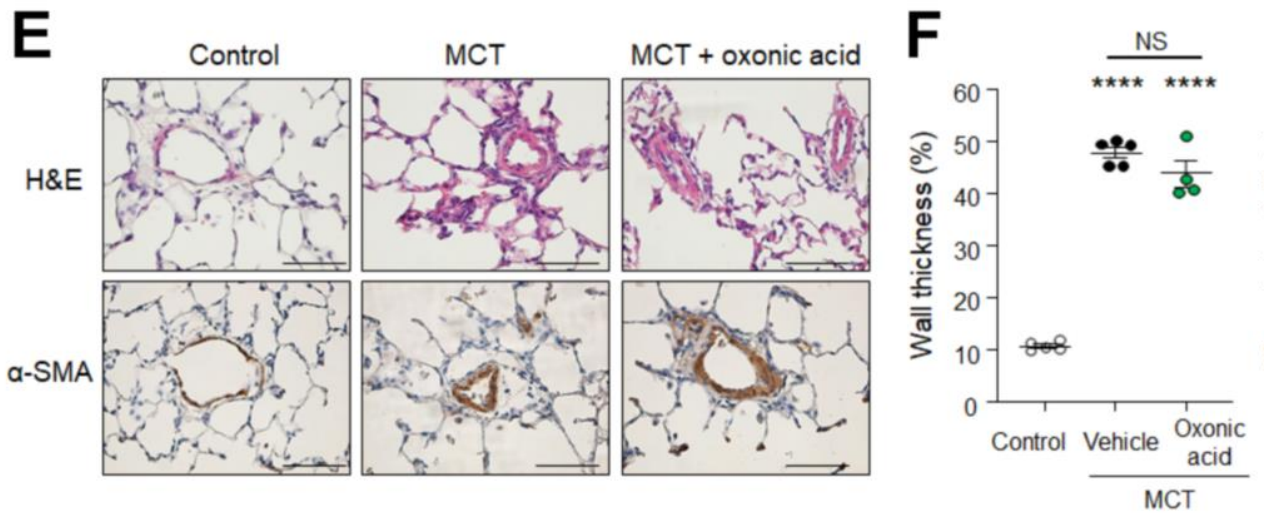

$\frac{\text { NS }}{\star \star \star \star \star \star \star \star \star \star}$

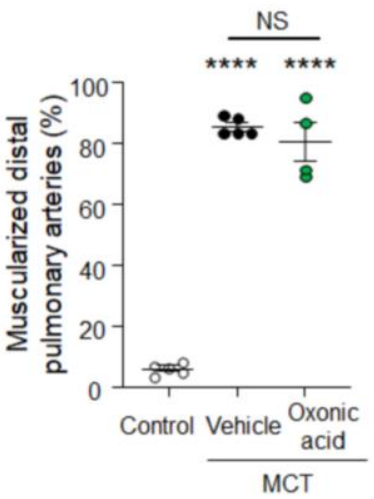


A

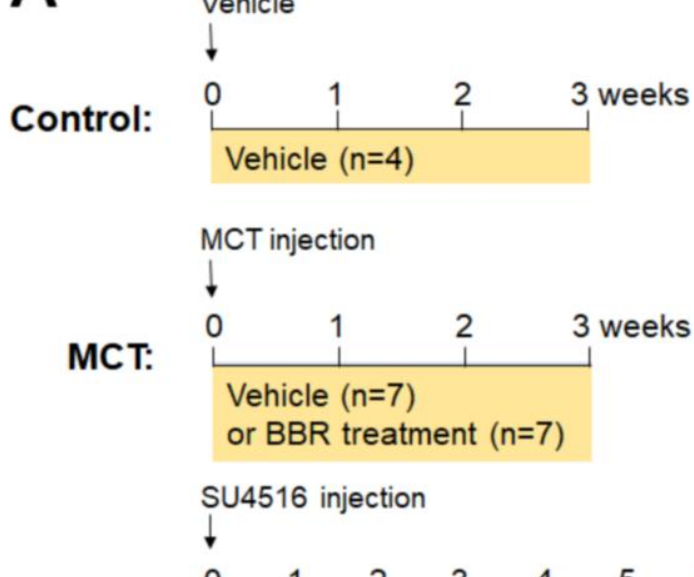

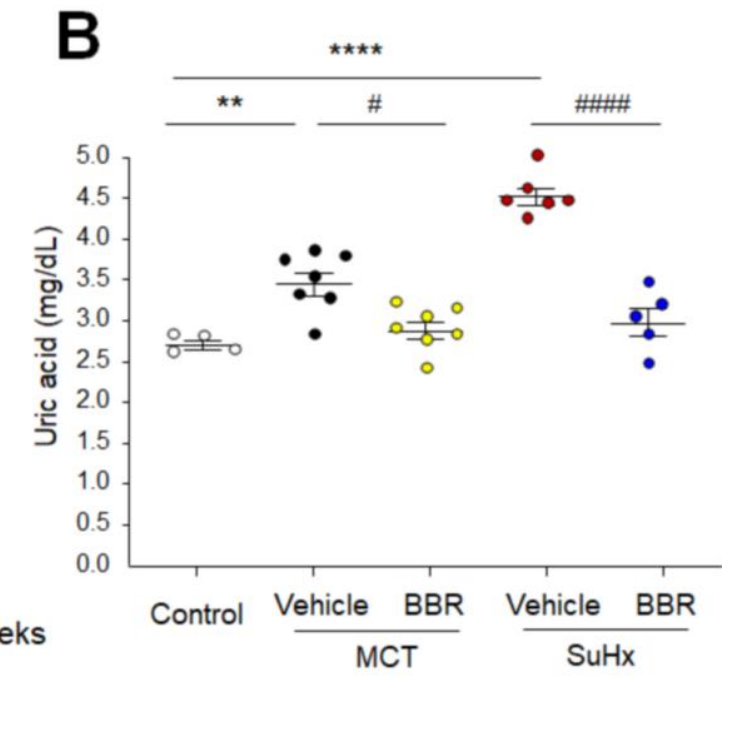

SuHx:
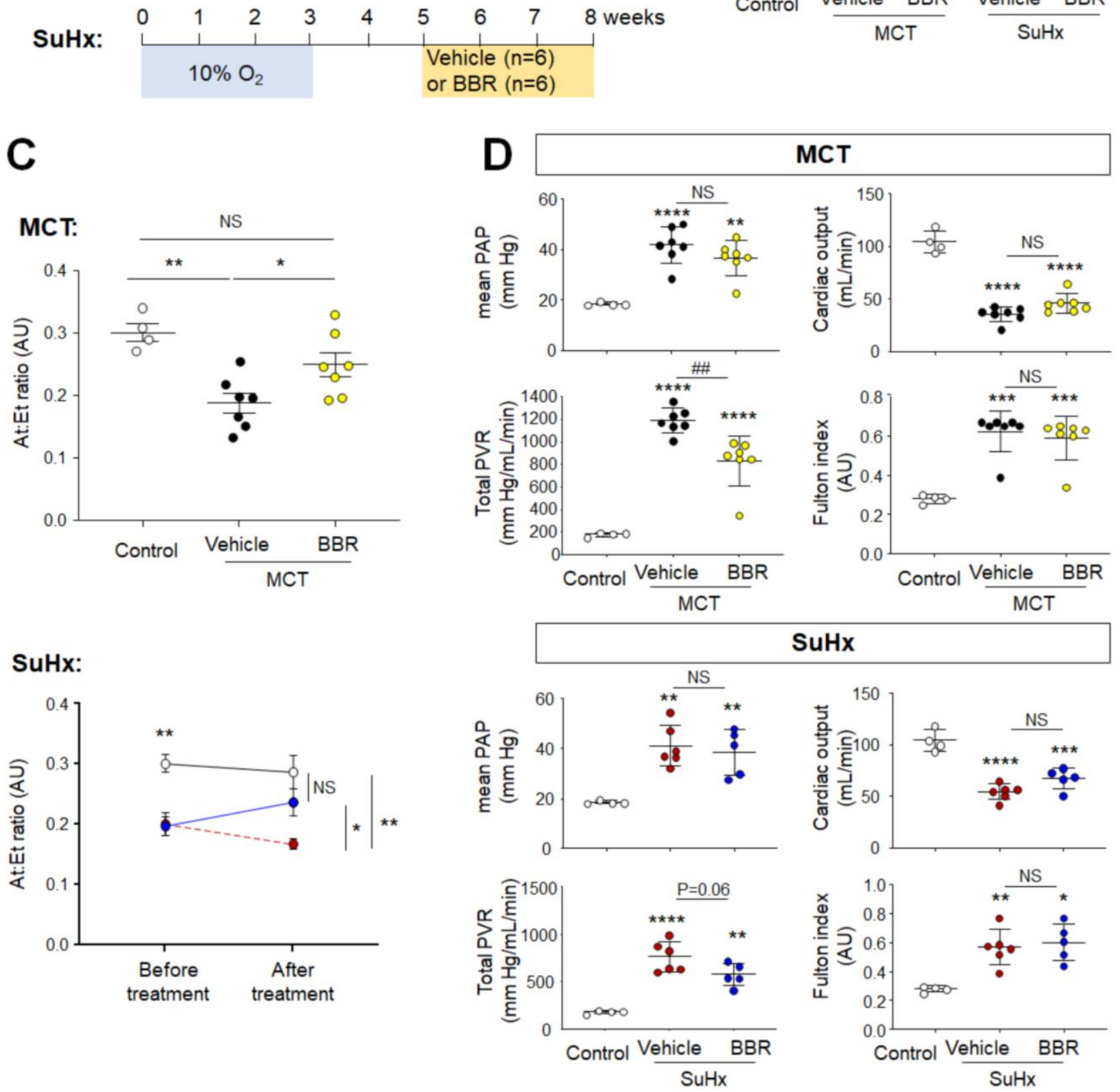

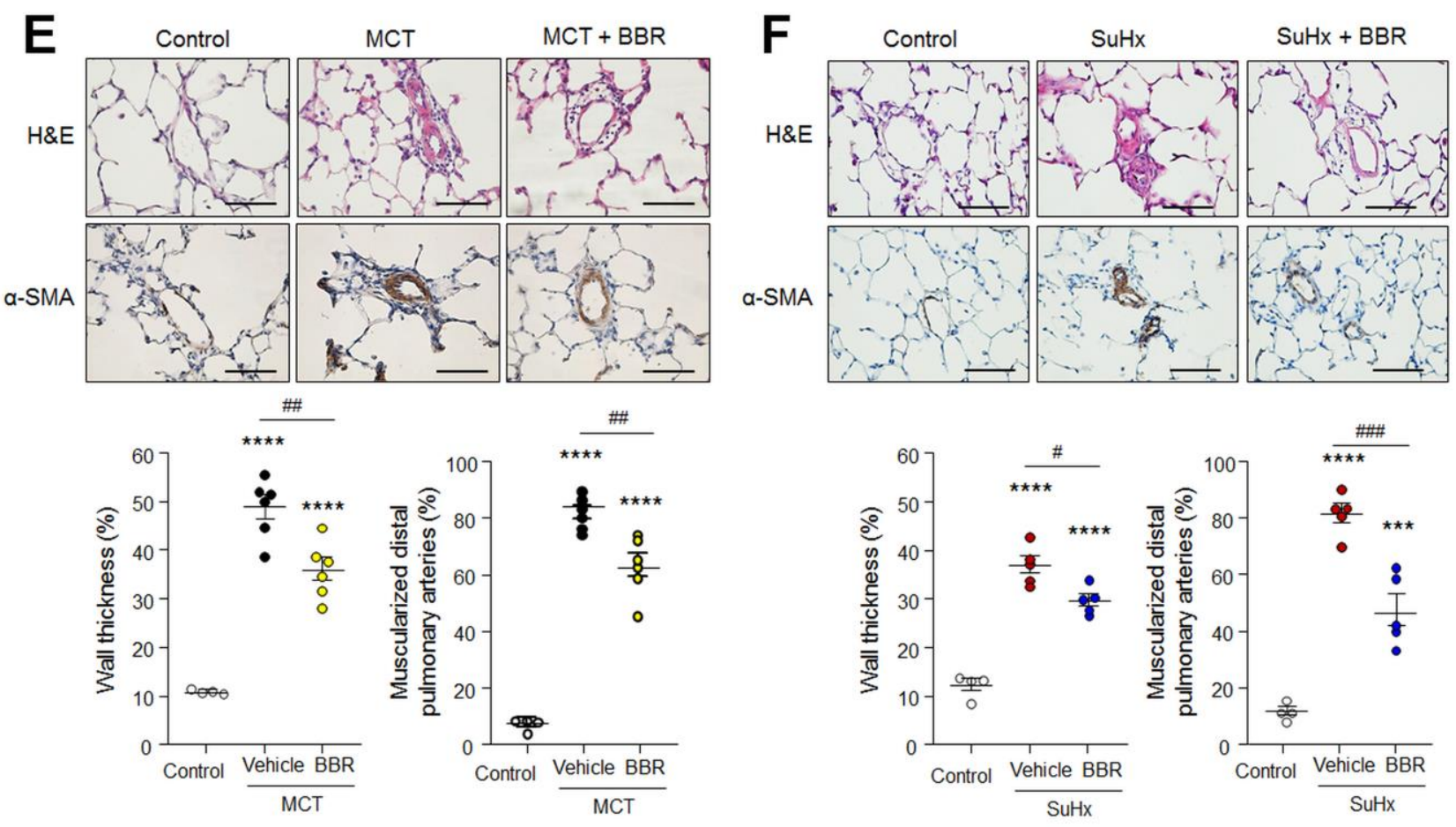
Table 1. Characteristics at baseline and first follow-up according to UA level.

\begin{tabular}{|c|c|c|c|c|c|c|}
\hline & \multicolumn{3}{|c|}{ Baseline } & \multicolumn{3}{|c|}{ First re-evaluation } \\
\hline & $\begin{array}{c}\text { UA }< \\
\text { baseline } \\
\text { median value }\end{array}$ & $\begin{array}{c}\text { UA } \geq \\
\text { baseline } \\
\text { median } \\
\text { value }\end{array}$ & $\begin{array}{c}p \\
\text { value }\end{array}$ & $\begin{array}{c}\text { UA< } \\
\text { baseline } \\
\text { median } \\
\text { value }\end{array}$ & $\begin{array}{c}\mathrm{UA} \geq \\
\text { baseline } \\
\text { median } \\
\text { value }\end{array}$ & $\begin{array}{c}p \\
\text { value }\end{array}$ \\
\hline Number of patients, $\mathrm{n}$ & 165 & 165 & & 82 & 81 & \\
\hline Age, years & $57 \pm 18$ & $58 \pm 17$ & 0.62 & $50 \pm 18$ & $57 \pm 17$ & 0.01 \\
\hline Body Mass Index, $\mathrm{kg} \cdot \mathrm{m}^{-2}$ & $27 \pm 6$ & $29 \pm 7$ & 0.03 & $27 \pm 6$ & $29 \pm 7$ & 0.06 \\
\hline Hypertension, n (\%) & $76(46)$ & $82(50)$ & 0.5 & $28(34)$ & $43(53)$ & 0.01 \\
\hline Diabetes, n (\%) & $10(6)$ & $25(15)$ & 0.007 & $7(9)$ & $24(30)$ & $<0.001$ \\
\hline $\begin{array}{l}\text { NYHA-FC, } n \text { (\%) } \\
\text { I / II } \\
\text { III / IV }\end{array}$ & $\begin{array}{c}53(30) \\
112(70)\end{array}$ & $\begin{array}{l}38(19) \\
127(81)\end{array}$ & 0.06 & $\begin{array}{l}58(71) \\
24(29)\end{array}$ & $\begin{array}{l}52(64) \\
29(36)\end{array}$ & 0.3 \\
\hline 6-MWD, m & $339 \pm 127$ & $297 \pm 142$ & 0.005 & $427 \pm 128$ & $359 \pm 134$ & 0.001 \\
\hline $\begin{array}{l}\mathrm{BNP} \geq 50 \mathrm{ng} \cdot \mathrm{L}^{-1} \text { or } \mathrm{NT}- \\
\text { proBNP } \geq 300 \mathrm{ng} \cdot \mathrm{L}^{-1}, n(\%)\end{array}$ & 101/133 (76) & 118/137 (86) & 0.03 & $30 / 72(42)$ & $49 / 74(66)$ & 0.18 \\
\hline Hemodynamics & & & & & & \\
\hline $\mathrm{RAP}, \mathrm{mmHg}$ & $8 \pm 5$ & $10 \pm 4$ & 0.002 & $6 \pm 4$ & $8 \pm 5$ & 0.08 \\
\hline Mean PAP, $m m H g$ & $50 \pm 13$ & $50 \pm 11$ & 0.76 & $42 \pm 12$ & $44 \pm 10$ & 0.24 \\
\hline PAWP, $m m H g$ & $10 \pm 4$ & $10 \pm 4$ & 0.66 & $10 \pm 4$ & $10 \pm 5$ & 0.66 \\
\hline $\mathrm{CO}$, L. $\mathrm{min}^{-1}$ & $4.4 \pm 1.2$ & $4.2 \pm 1.3$ & 0.15 & $5.7 \pm 1.9$ & $5.4 \pm 1.5$ & 0.24 \\
\hline $\mathrm{Cl}$, L. $\mathrm{min}^{-1}$ per $\mathrm{m}^{2}$ & $2.5 \pm 0.6$ & $2.3 \pm 0.6$ & 0.006 & $3.2 \pm 0.9$ & $2.9 \pm 0.8$ & 0.10 \\
\hline PVR, Wood Units & $10 \pm 5$ & $11 \pm 5$ & 0.08 & $6.3 \pm 3.2$ & $6.8 \pm 2.9$ & 0.31 \\
\hline $\begin{array}{l}\text { PAH Therapies, } \mathrm{n}(\%) \\
\text { Monotherapy } \\
\text { Combotherapies }\end{array}$ & - & - & - & $\begin{array}{l}38(46) \\
44(54)\end{array}$ & $\begin{array}{l}28(36) \\
53(64)\end{array}$ & 0.12 \\
\hline Diuretics, $\mathrm{n}(\%)$ & $91(55)$ & $127(77)$ & $<0.001$ & $46(56)$ & $60(74)$ & 0.03 \\
\hline
\end{tabular}

Data are presented as mean \pm SD.

Abbreviations: 6-MWD, 6 minutes-walk distance; BNP, brain natriuretic peptide; NT-proBNP, N-terminal pro hormone fragment; $\mathrm{Cl}$, cardiac index; $\mathrm{CO}$, cardiac output; NYHA, Modified New York Heart Association functional class; PAP, pulmonary artery pressure; PAWP, pulmonary artery wedge pressure; PVR, pulmonary vascular resistance; RAP, right atrial pressure.

The baseline median value or UA level was $8.2 \mathrm{mg} / \mathrm{dL}$ (IQR; 6.9-9.7) in male and $7.3 \mathrm{mg} / \mathrm{dL}$ (IQR; 5.9-8.8) in female at baseline. 
Table 2. Multivariable analysis for baseline and follow-up factors and overall survival

\begin{tabular}{|c|c|c|c|c|}
\hline & \multicolumn{2}{|c|}{ Baseline } & \multicolumn{2}{|c|}{ First re-evaluation } \\
\hline & HR $(95 \% \mathrm{Cl})$ & p value & $\mathrm{HR}(95 \% \mathrm{Cl})$ & p value \\
\hline \multicolumn{5}{|c|}{ Prognostic value of UA adjusted for age, sex, BMI and comorbidities } \\
\hline & \multicolumn{2}{|l|}{$\mathrm{n}=328$} & \multicolumn{2}{|l|}{$\mathrm{n}=154$} \\
\hline Uric acid, $m g / d L$ & $1.000(0.999-1.002)$ & 0.52 & $1.002(1.000-1.005)$ & 0.067 \\
\hline Age, years & $1.048(1.034-1.062)$ & $<0.0001$ & $1.037(1.016-1.058)$ & 0.0004 \\
\hline Sex, female vs male & $0.671(0.475-0.947)$ & 0.0234 & $1.088(0.617-1.918)$ & 0.77 \\
\hline BMI, kg.m² & $0.998(0.968-1.029)$ & 0.89 & $0.941(0.896-0.989)$ & 0.016 \\
\hline Hypertension, yes vs no & $1.036(0.713-1.506)$ & 0.85 & $1.664(0.864-3.195)$ & 0.13 \\
\hline Diabetes, yes vs no & $1.050(0.591-1.866)$ & 0.86 & $1.331(0.649-2.725)$ & 0.43 \\
\hline \multicolumn{5}{|c|}{ Prognostic value of UA adjusted for hemodynamic variables } \\
\hline & \multicolumn{2}{|l|}{$\mathrm{n}=314$} & \multicolumn{2}{|l|}{$n=153$} \\
\hline Uric acid, $m g / d L$ & $1.000(0.999-1.002)$ & 0.43 & $1.004(1.001-1.006)$ & 0.0019 \\
\hline $\mathrm{RAP}, \mathrm{mmHg}$ & $1.034(0.995-1.073)$ & 0.09 & $0.991(0.904-1.086)$ & 0.842 \\
\hline PAWP, mmHg, meters & $0.985(0.939-1.034)$ & 0.54 & $1.089(1.009-1.174)$ & 0.028 \\
\hline $\mathrm{mPAP}, \mathrm{mmHg}$ & $0.981(0.965-0.997)$ & 0.0177 & $1.005(0.976-1.034)$ & 0.76 \\
\hline $\mathrm{Cl}, \mathrm{l} / \mathrm{min} / \mathrm{m}^{2}$ & $0.861(0.629-1.179)$ & 0.35 & $0.603(0.411-0.883)$ & 0.0094 \\
\hline \multicolumn{5}{|c|}{ Prognostic value of UA adjusted for non-invasive prognostic variables } \\
\hline & \multicolumn{2}{|l|}{$n=256$} & \multicolumn{2}{|l|}{$\mathrm{n}=142$} \\
\hline Uric acid, $m g / d L$ & $1.000(0.999-1.001)$ & 0.98 & $1.001(0.999-1.003)$ & 0.45 \\
\hline NYHA-FC, III-IV vs I-II & $1.117(0.683-1.828)$ & 0.66 & $2.242(1.274-3.952)$ & 0.0051 \\
\hline $6 \mathrm{MWD}, \mathrm{m}$ & $0.995(0.994-0.997)$ & $<0.0001$ & $1.004(1.001-1.006)$ & 0.0021 \\
\hline BNP or NTproBNP, high vs low & $1.499(0.805-2.785)$ & 0.20 & $3.144(1.433-6.896)$ & 0.0043 \\
\hline \multicolumn{5}{|c|}{ Prognostic value of UA adjusted for therapies } \\
\hline & \multicolumn{2}{|l|}{$\mathrm{n}=310$} & \multicolumn{2}{|l|}{$\mathrm{n}=161$} \\
\hline Uric acid, $\mathrm{mg} / \mathrm{dL}$ & $1.001(0.998-1.005)$ & 0.30 & $1.003(1.001-1.005)$ & 0.004 \\
\hline Diuretics, yes vs no & $1.901(0.562-6.493)$ & 0.38 & $0.545(0.282-1.057)$ & 0.07 \\
\hline Combotherapies, yes vs no & - & - & $1.128(0.651-1.952)$ & 0.69 \\
\hline
\end{tabular}

Abbreviations: 6-MWD, 6 minutes-walk distance; BMI, body mass index; BNP, brain natriuretic peptide; NT-proBNP, N-terminal pro hormone fragment; $\mathrm{Cl}$, cardiac index; $\mathrm{CO}$, cardiac output; NYHA, Modified New York Heart Association functional class; PAP, pulmonary artery pressure; PAWP, pulmonary artery wedge pressure; PVR, pulmonary vascular resistance; RAP, right atrial pressure.

For each model, the HR represent the HRs for each variable with adjustment for all other listed variables. 


\title{
Online data supplement
}

\section{Serum and Pulmonary Uric Acid in Pulmonary Arterial Hypertension}

\author{
Running title: Savale et al.; Role of Urate in PAH
}

Laurent Savale 1,2,3, Satoshi Akagi ${ }^{1,2}$, Ly Tu1,2, Amélie Cumont ${ }^{1,2}$, Raphaël Thuillet ${ }^{1,2}$, Carole Phan ${ }^{1,2}$, Benjamin Le Vely ${ }^{1,2}$, Nihel Berrebeh ${ }^{1,2}$, Alice Huertas ${ }^{1,2,3}$, Xavier Jaïs ${ }^{1,2,3}$, Vincent Cottin $^{4}$, Ari Chaouat ${ }^{5}$, Cécile Tromeur ${ }^{6}$, Athénaïs Boucly ${ }^{1,2,3}$, Etienne Marie Jutant ${ }^{1,2,3}$, Olaf Mercier $^{1,2,7}$, Elie Fadel ${ }^{1,2,7}$, David Montani ${ }^{1,2,3}$, Olivier Sitbon ${ }^{1,2,3}$, Marc Humbert ${ }^{1,2,3}$, Yuichi Tamura $^{1,2,8}$, Christophe Guignabert ${ }^{1,2}$ 


\section{Figure legend}

Supplemental figure 1: Expressions of xanthine oxidase (XO) and URATv1 in human pulmonary endothelial cells (ECs) in idiopathic pulmonary arterial hypertension (iPAH). (A) Representative Western blots and quantification of the XO:GADPH and URATV1:GAPDH ratios in cultured pulmonary ECs derived from control and iPAH patients. (B) Conditioned media from $24 \mathrm{~h}$ serum starved pulmonary ECs were measured for secreted UA levels using a specific uric acid assay. Data are presented as mean \pm SEM $(n=5-11)$. Comparisons were made using the nonparametric Mann-Whitney $U$ test. * $p$-value $<0.05$ versus control PA-ECs. $\mathrm{AU}=$ arbitrary unit.

Supplemental Figure 2: High uric acid (UA) concentrations promote reactive oxygen species (ROS) production in pulmonary artery smooth muscle cells (PA-SMCs) derived from patients with idiopathic pulmonary arterial hypertension (iPAH).

Representative images and quantification of the intracellular ROS generation using fluoregenic probes dihydroethidium (DHE) in control and iPAH PA-SMCs treated 30 minutes with UA at the indicated doses.

Supplemental Figure 3: (A) Values of mean pulmonary arterial pressure (mPAP), cardiac output, total pulmonary vascular resistance (PVR), and of Fulton index in control and MCTinjected rats (B) Representative images of $\alpha$-smooth muscle (SM) actin-stained sections of distal pulmonary arteries and quantification of the percentage of wall thickness and of muscularized distal pulmonary arteries in lungs of control and MCT-injected rats. Scale bar = $20 \mu \mathrm{m}$ in all sections. Values are means \pm SEM $(n=4-5)$. Comparisons were made using 1-way ANOVA with Tukey's post hoc tests. ${ }^{*} p$-value $<0.05$, ${ }^{* *} p$-value $<0.01$, ${ }^{* * * *} p$-value $<0.0001$ compared with control rats. $\mathrm{AU}=$ arbitrary unit.

Supplemental Figure 4: (A) Levels of uric acid (UA) in the serum of control animals, monocrotaline (MCT)-injected at Day-21 post-MCT injection $(n=7-10)$. (B) Representative Western blots and quantification of the XO:GADPH and URATV1:GAPDH ratios in lungs of control, and MCT-injected rats $(n=7-10)$. Horizontal lines display the mean \pm SEM. Comparisons were made using 1-way ANOVA with Tukey's post hoc tests/ * $p$-value $<0.05$, ** $p$-value $<0.01,{ }^{* * *} p$-value $<0.001$, compared with control. $A U=$ arbitrary unit. 
Supplemental Table 1: univariate analysis for transplant-free survival

\begin{tabular}{|c|c|c|c|c|}
\hline & \multicolumn{2}{|l|}{ baseline } & \multicolumn{2}{|c|}{ First re-evaluation } \\
\hline & HR (95\% CI) & $P$ value & HR (95\% CI) & $P$ value \\
\hline Age, years & $1.049(1.036-1.062)$ & $<0.0001$ & $1.047(1.029-1.065)$ & $<0.0001$ \\
\hline Sex, female vs male & $0.574(0.490-0.803)$ & 0.001 & $0.680(0.404-1.145)$ & 0.15 \\
\hline BMI, $\mathrm{kg} / \mathrm{m}^{2}$ & $1.007(0.982-1.033)$ & 0.58 & $0.976(0.934-1.019)$ & 0.27 \\
\hline Hypertension, yes vs no & $0.535(0.380-0.752)$ & 0.003 & $3.344(1.953-5.714)$ & $<0.0001$ \\
\hline Diabetis, yes vs no & $0.749(0.436-1.284)$ & 0.29 & $2.347(1.312-4.201)$ & 0.004 \\
\hline NYHA-FC, $I I I-I V$ vs $I-I I$ & $1.625(1.072-2.462)$ & 0.02 & $3.367(2.008-5.649)$ & $<0.0001$ \\
\hline 6-min WD, meters & $0.995(0.994-0.997)$ & $<0.0001$ & $0.994(0.992-0.996)$ & $<0.0001$ \\
\hline $\mathrm{RAP}, m m H g$ & $1.025(0.992-1.059)$ & 0.14 & $1.062(1.008-1.118)$ & 0.02 \\
\hline PCWP, $m m H g$ & $0.991(0.952-1.032)$ & 0.66 & $1.065(1.010-1.123)$ & 0.02 \\
\hline mPAP, $m m H g$ & $0.987(0.973-1.001)$ & 0.07 & $1.014(0.990-1.038)$ & 0.27 \\
\hline Cardiac index, l.min. $m^{2}$ & $0.873(0.658-1.158)$ & 0.34 & $0.597(0.405-0.880)$ & 0.009 \\
\hline PVR, $W U$ & $0.997(0.964-1.032)$ & 0.88 & $1.073(0.999-1.152)$ & 0.05 \\
\hline $\mathrm{BNP}$ or NTproBNP, high vs low & $2.088(1.144-3.802)$ & 0.016 & $5.882(2.873-12.048)$ & $<0.0001$ \\
\hline Uric acid, > median value & $0.846(0.603-1.186)$ & 0.33 & $1.754(1.039-2.967)$ & 0.03 \\
\hline Uric acid, $\mathrm{mg} / \mathrm{dL}$ & $1.001(1.000-1.002)$ & 0.18 & $1.004(1.002-1.006)$ & 0.0003 \\
\hline Diuretics, yes vs no & & & $2.381(1.262-4.504)$ & 0.007 \\
\hline PAH therapies, mono vs combo & - & - & $0.769(0.511-1.534)$ & 0.66 \\
\hline
\end{tabular}


Supplemental Fig. 1
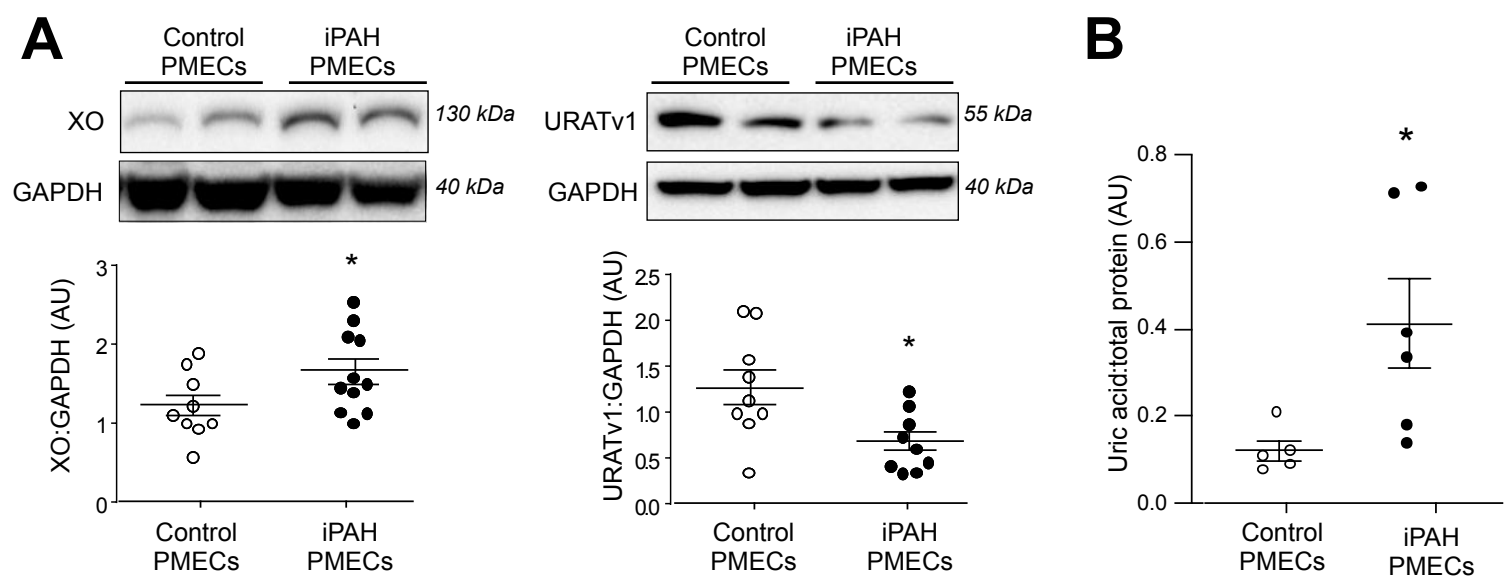
Supplemental Fig. 2

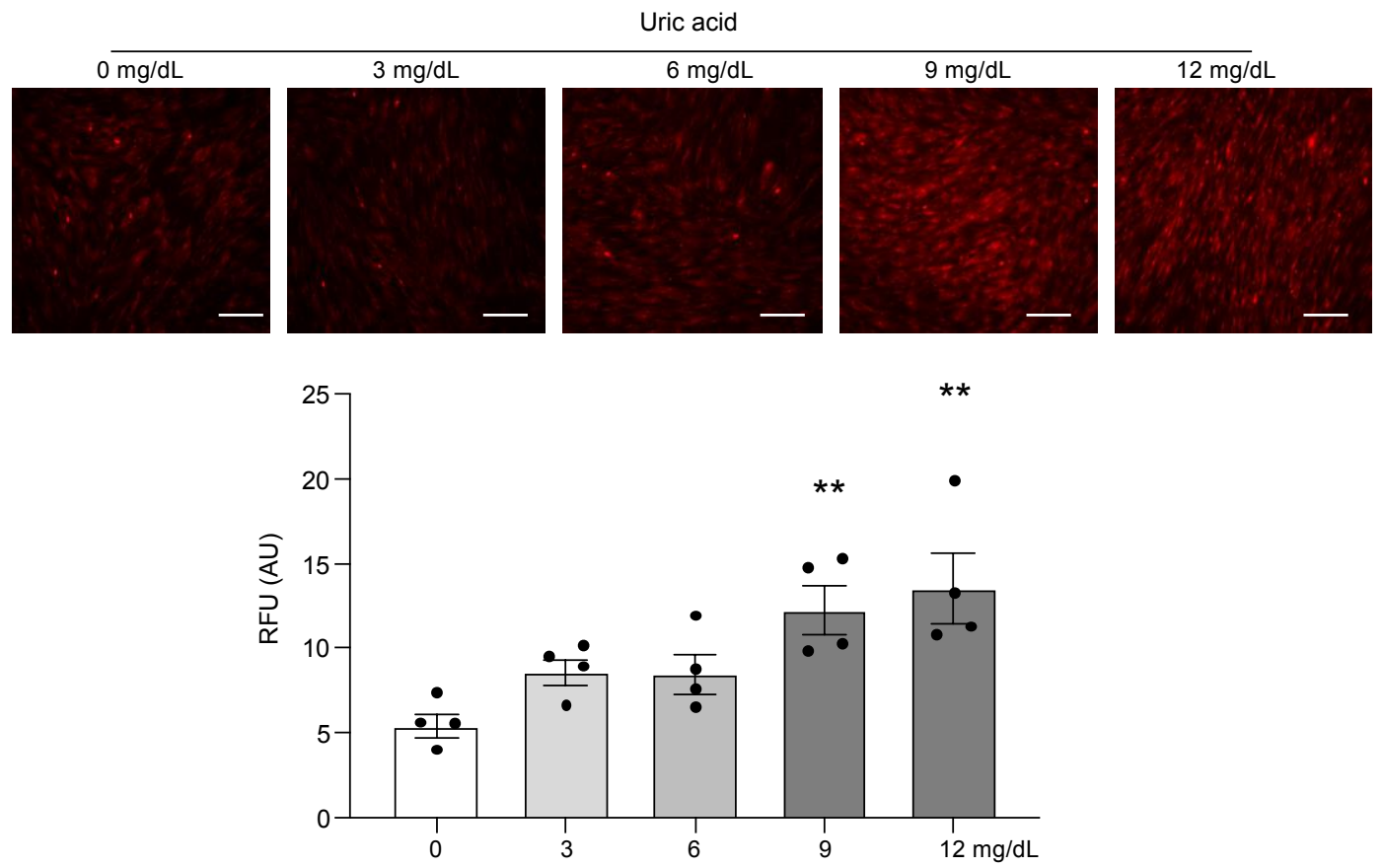




\section{Supplemental Fig. 3}

A
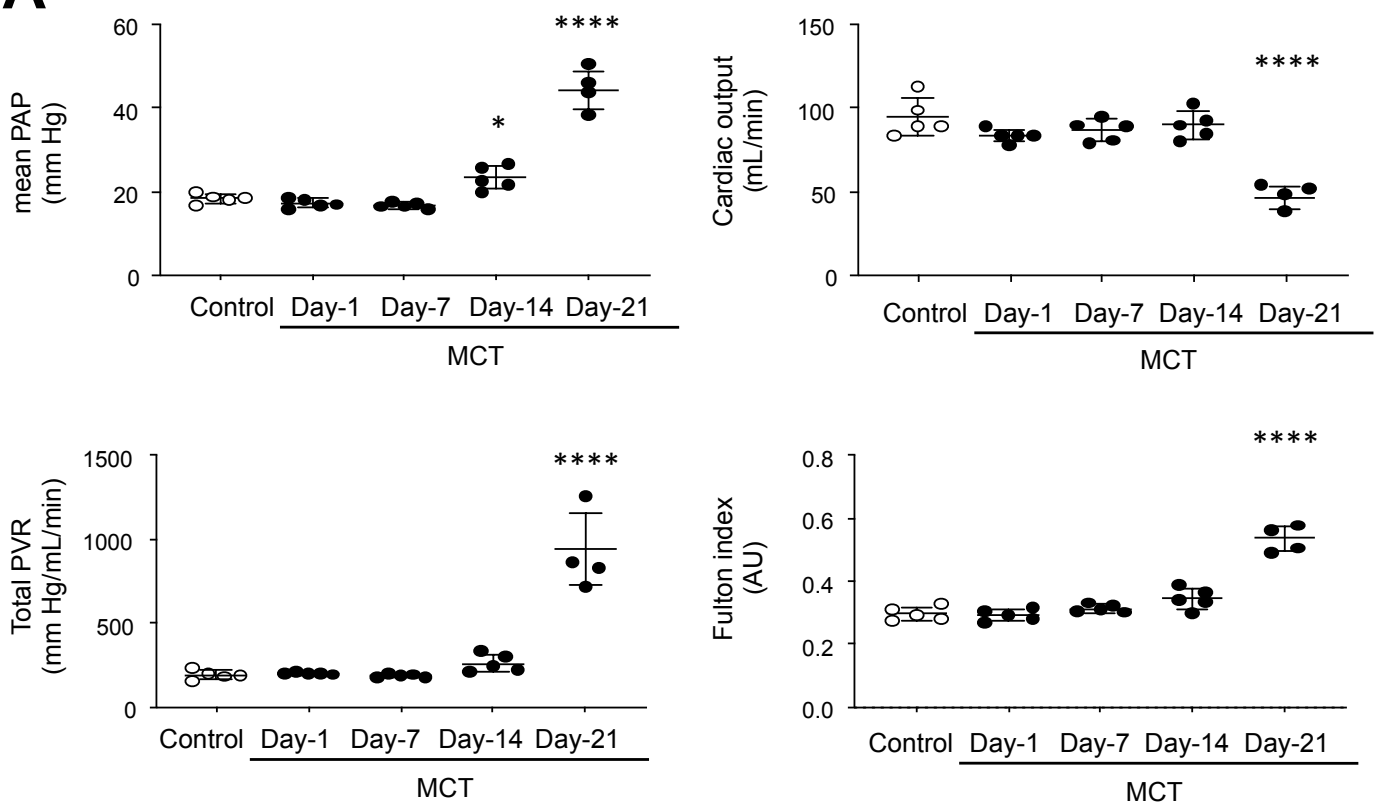

B
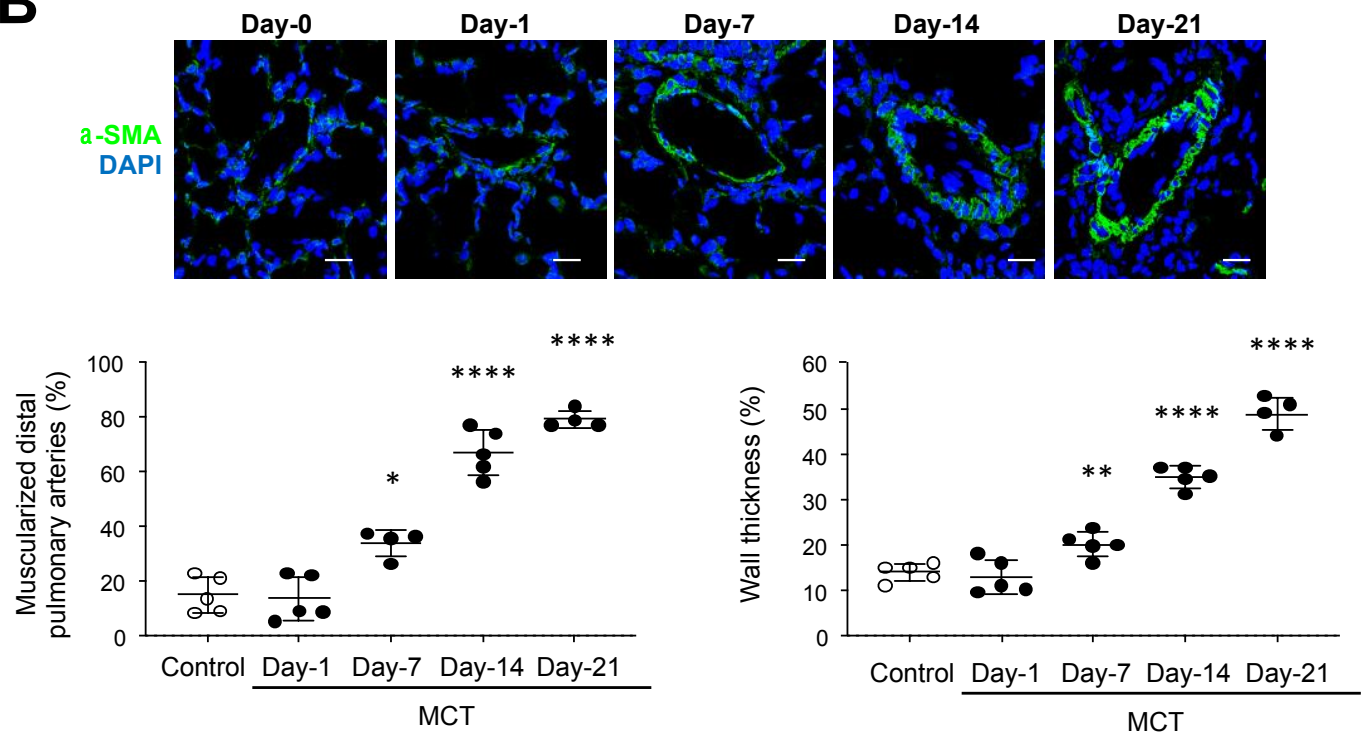
Supplemental Fig. 4
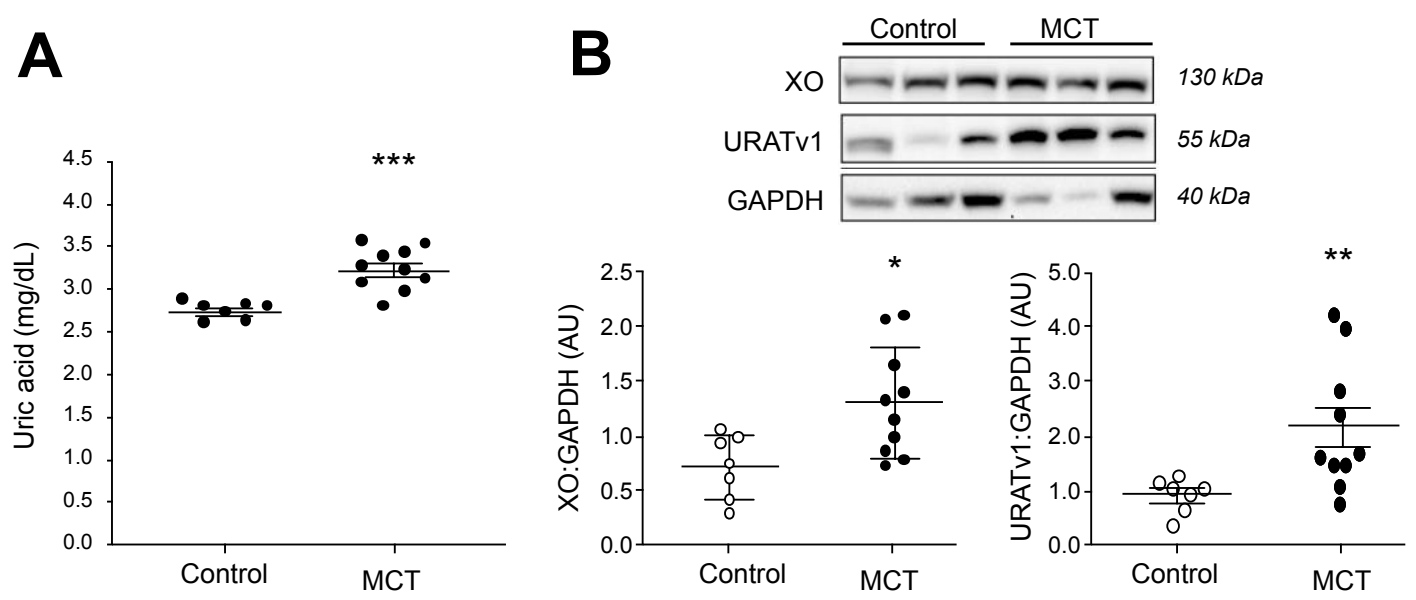